\title{
دراسة تحليلية لتدفقات التجارة الخارجية بين مصر ودول الكوميسا باستخدام نموذج الجاذ الجاذبية
}

\author{
ياسر عبد الحميد عبد الراضى وعي كلئ \\ أستاذ الاقتصاد الزراعى وعميد كلية الزراعة والموارد الطبيعية- جامعة أسوان الريل

$$
\text { حسين حسن على أدم }
$$

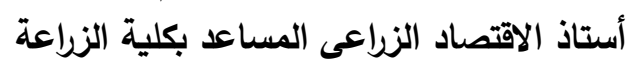 \\ جامعة أسوان
}

حسن سعود سعيد هليل الثريجة

طالب دكتوراة بمعهر البحوث والدراسات الافريقية هلية الفئة

جامعة أسوان 


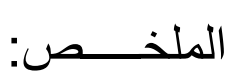

تتبلور مشكلة الدراسة فى انه على الرغم من انضمام مصر الى الكوميسا منذ

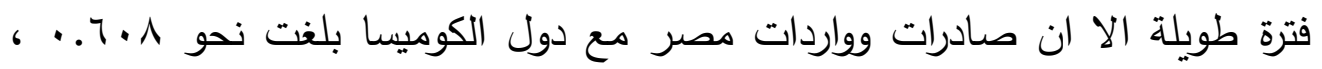

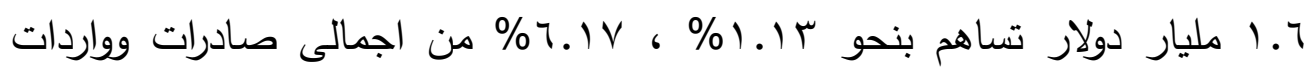

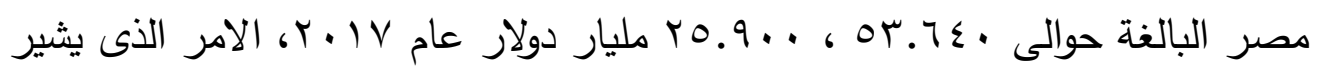

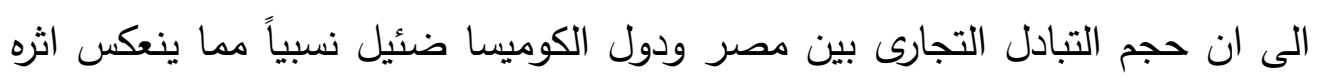
فى صعوبة الحصول على التقد الاجنبى اللازم لدفع عجلة التتمية الاقتصادية، ويستهدف البحث كيفية زيادة حجم التبادل بين مصر والكوميسا، في ضوء الإرتباط الإقليمي والمكانى بينهه، والتعرف على أهم العوامل المؤثرة على التجارة الخارجية لمصر مع الكوميسا، وأيضا الوقوف على أهم الدول التي تتوسع أو تحد في وارداتها

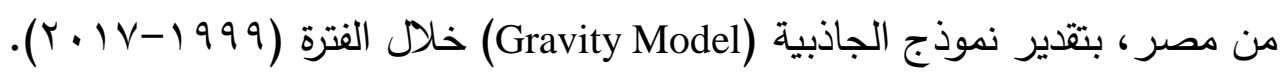
وتبين من نتائج نموذج الجاذبية الاساسي للصادرات لقياس الاثر الاجمالى

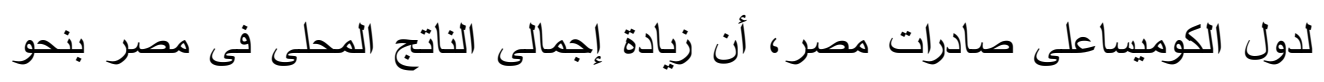

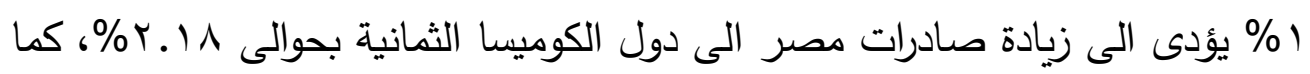

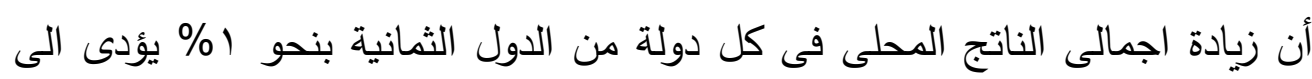

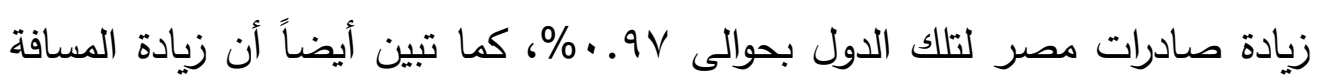

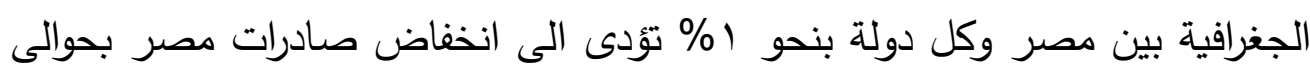

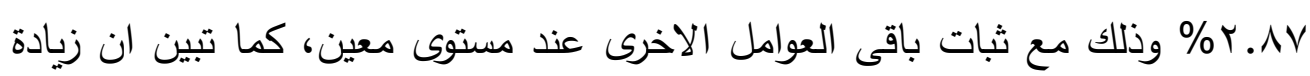

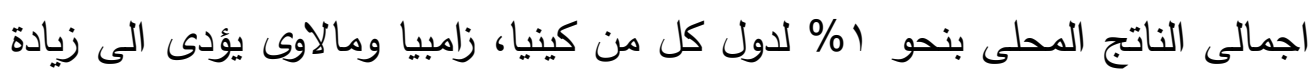

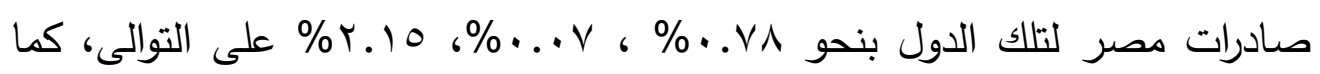

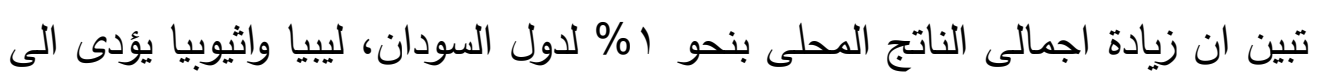

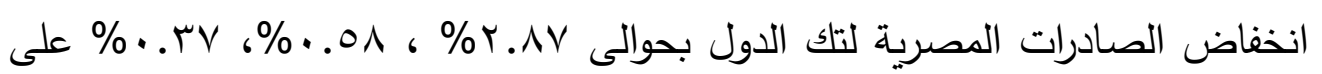
التوالى. 
وتبين من نتائج نموذج الجاذبية الاساسي لصادرات مصر الزراعية، لقياس الاثر الاجمالى لدول الكوميسا على صادرات مصر الزراعية، أن زيادة إجمالى الناتج المحلى فى مصر بنحو ا \% يؤدى الى زيادة صادرات مصر الزراعية الى دول الكوميسا الخمسة بحوالى 790 . • \%، كما أن زيادة اجمالى الناتج المحلى فى كل دولة من الدول الخمسة بنحو ا \% يؤدى الى زيادة صادرات مصر الزراعية لهم بحوالى

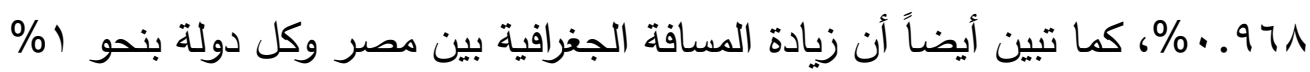

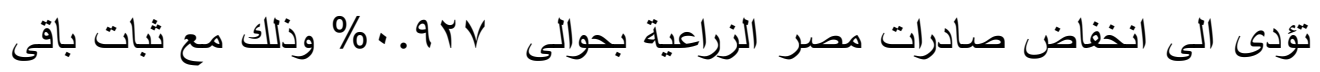
العوامل الاخرى عند مستوى معين.

وفى ضوء ما سبق:

أوصت نتائج البحث بضرورة تطوير مشروعات البنية الأساسية المشتركة، وتحسين وسائل النقل بين مصر ودول الكوميسا، ولا سيما مع دول الجوار ليبيا والسودان، مع دراسة الأسواق الداخلية لها، حتى يمكن تصدير سلع وخدمات مصرية تراعى ذوق المستهلك الأفريقي ومتطلبات الجودة من خلال دراسة الاسواق الداخلية لدول الكوميسا، وإنثاء منطقة مشتركة للإستثمار بين دول الكوميسا.

الكلمات المفتاحية: التجارة الخارجية - دول الكوميسا - دول حوض النيل

\section{Abstract:}

The problem of the study is that although Egypt joined COMESA a long time ago, Egypt's exports and imports with COMESA countries amounted to about $0.608,1.6$ billion dollars, contributing about $1.13 \%, 6.17 \%$ of Egypt's total exports and imports of about 53.640, 25.900 billion dollars a year. 2017, which indicates that the volume of trade exchange between Egypt and the COMESA countries is relatively small, which reflects its impact on the difficulty of obtaining foreign exchange necessary to advance the economic 


\section{ياسر عبدالر اضى و آخرون، دراسة تحليلية لتدفقات التجارة الخارجية بين مصر ودول الكوميسا.}

development, and the research aims at how to increase the volume of exchange between Egypt and COMESA, in light of the regional and locational link between them, and to get to know The most important factors affecting Egypt's foreign trade with COMESA, as well as identifying the most important countries that expand or limit their imports from Egypt, by estimating the Gravity Model during the period (1999-2017).

It was clear from the results of the basic gravity model of exports to measure the total impact of the COMESA countries on Egypt's exports, that an increase of the gross domestic product in Egypt by about $1 \%$ leads to an increase in Egypt's exports to the eight COMESA countries by about $2.18 \%$, and that the increase of the gross domestic product in each of the eight countries About 1\% leads to an increase in Egypt's exports to these countries by about $0.97 \%$. It also turned out that an increase in the geographical distance between Egypt and each country by about 1\% leads to a decrease in Egypt's exports by about $2.87 \%$, with the remaining factors remaining at a certain level, as it was found that an increase The GDP of about $1 \%$ for the countries of Kenya, Zambia and Malawi leads to an increase in Egypt's exports to these countries by $0.78 \%, 0.07 \%, 2.15 \%$, respectively, as it was found that an increase in the gross domestic product by $1 \%$ for the countries of Sudan, Libya and Ethiopia leads to a decrease Egyptian exports to these countries increased by $2.87,0.58 \%$ and $0.37 \%$, respectively

It was clear from the results of the basic gravity model of Egypt's agricultural exports, to measure the total impact of COMESA countries on Egypt's agricultural exports, that an increase of the gross domestic product in Egypt by about $1 \%$ leads to an increase in Egypt's agricultural exports to the five COMESA countries by about $0.695 \%$, and that the increase in the gross 
domestic product In each of the five countries by about $1 \%$, it leads to an increase in Egypt's agricultural exports to them by about $0.968 \%$, as it was also shown that an increase in the geographical distance between Egypt and each country by about $1 \%$ leads to a decrease in Egypt's agricultural exports by about $0.927 \%$, with the stability of the rest of the other factors at Specific level .

\section{In light of the above, the research recommends the following:}

The results of the research recommended the necessity of developing joint infrastructure projects and improving transportation between Egypt and the COMESA countries, especially with neighboring countries Libya and Sudan, while studying the internal markets for them, so that Egyptian goods and services can be exported that take into account the African consumer taste and quality requirements by studying the internal markets of COMESA, and the establishment of a common area for investment among the COMESA countries.

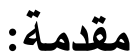

تعتبر السوق المشتركة لشرق وجنوب أفريقيا (كوميسا)، واحدة من أكبر

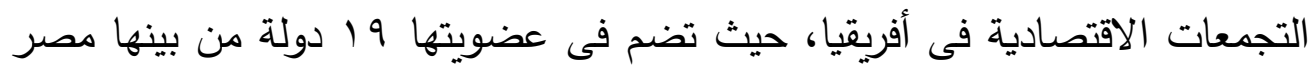
التى انضمت لها فى منتصف 1991، وتهدف الى تتمية موارد الدول الاعضاء الطبيعية والبشرية من أجل تحقيق الرفاهية الاقتصادية من خلال التكامل الاقليمى الذى

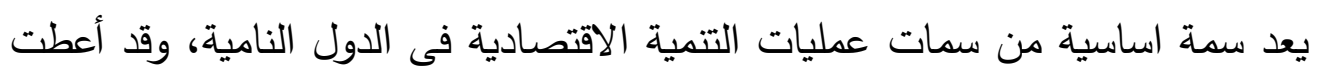
خبرة القارة الافريقية فى التكامل الاقليمى أولوية كبيرة للجوانب الاقتصادية لتحقيق لهيق

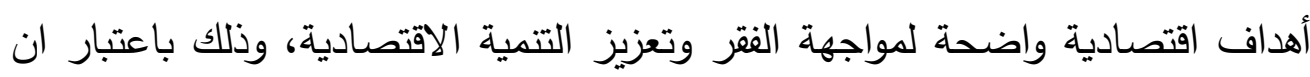
التكامل الاقتصادى من شأنه أن يحسن معدلات التبادل التجارى بين دول القارة 
وبعضها البعض وبينها وبين دول العالم المختلفة، ولذلك فان زيادة قدرة الصادرات المصرية للنفاذ داخل اسواق دول الكوميسا متوقفة على قدرتها لتحقيق ميزة نسبية وتنافسية.

\section{المشكلة البحثية:}

وتتبلور مشكلة الدراسة فى انه على الرغم من انضمام مصر الى الكوميسا منذ

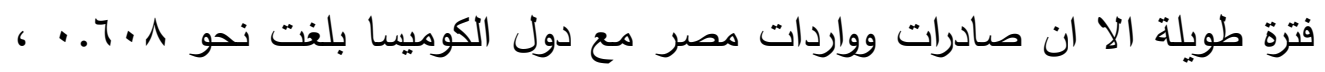

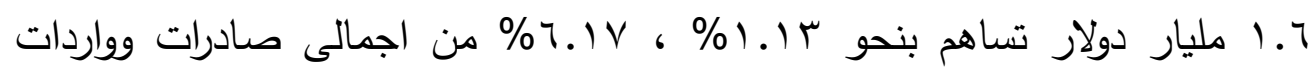

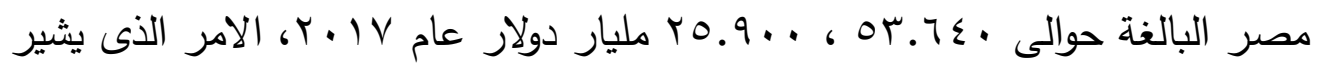
الى ان حجم التبادل التجارى بين مصر ودول الكوميسا ضئيل نسبياً مما ينعكس اثره فى صعوبة الحصول على التقد الاجنبى اللازم لدفع عجلة التنمية الاقتصادية.

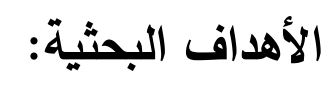
يستهدف البحث كيفية زيادة حجم التبادل بين مصر والكوميسا، في ضوء الإرتباط الإقليمي والمكانى بينهم، والتعرف على أهم العوامل المؤثرة على التجارة الخارجية لمصر مع الكوميسا، وأيضا الوقوف على أهم الدول التي تتوسع أو تحد في الإني وارداتها من مصر • الأسلوب البحثي:

تم تقدير نموذج الجاذبية (Gravity Model) بإستخدام أساليب إنحدار البيانات المقطعية والسلاسل الزمنية (Panel Data)، وتطبيق أسلوب التحليل المكانى (Spatial Analysis)، وأمكن الحصول على بيانات التجارة الخارجية المصرية مع ولطئية الكوميسا من الجهاز المركزي للتعبئة العامة والإحصاء، وقاعدة بيانات البنك الدولي

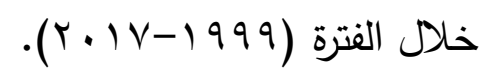




\section{الاطار النظرى لنموذج الجاذبية}

كان هناك اهتمام خاص بتفير التجارة الدولية من الناحية النظرية والتجريبية،

حيث تقوم تلك النظريات على فروض على المنافسة الاحتكارية واقتصاديات الحجم التى تقدم تفسيرا افضل لحقائق تجريبية فى التجارة الدولية، ويعتبر نموذج الجاذبية لقياس التجارة الدولية مشابه لقانون نيوتن الذى ينسب للتجاذب بين الجسمين الى كتلتيهما والمسافة بينهما، ووفقا لمفهوم الجاذبية فان التجارة الثنائية بين اقليمين تعنمد على دخلهما (GDP, GNP)، وتعتمد على المسافة بينهما بصورة عكسية، حيث

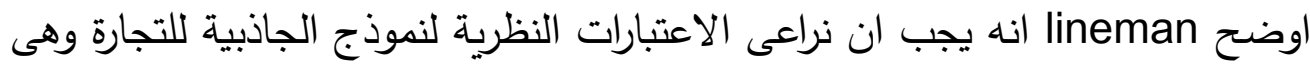

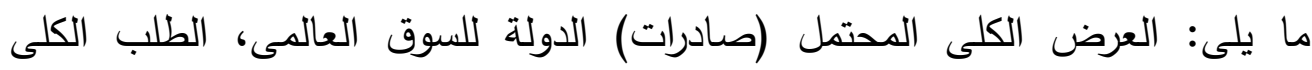
المحتمل (واردات) الدولة من السوق العالمى، والعوامل التى تخلق مقاومة للتجارة والعوامل المؤثرة فى درجة تركز التجارة.

وتعددت الدراسات القائمة على مفهوم الجاذبية المتضمن كل العوامل المؤثرة

$$
\text { على حجم التدفقات التجارية مثل ('): }
$$

أ - خلق التجارة فيما بين الدول الاعضاء وتحويل التجارة حيث اكدت الدراسات ان الزيادة فى حجم التدفقات التجارية نتيجة المناطق الحرة اكبر مما يستطيع ان يحققه اقتصاد كل دولة منفرداً.

ب - التدفقات التجارية فيما بين التكتلات مع اضافة متغيرات لتعبر عن قيمة التعريفة

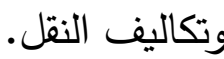

ج - قواعد المنشأ مع ضرورة أخذها بعين الاعتبار كمتغير يلى المسافة وحجم الدولة من حيث الأهمية.

د - معدلات الصرف والعوامل السياسية وأثر ذلك على تدفقات التجارة بين الدول. 
كما يعتمد نموذج الجاذبية فى تحديده على مجموعة من الاطر النظرية أهمها: الاطار

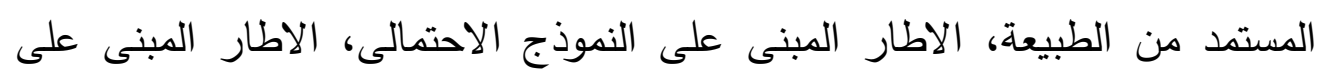
النظام الخطى للانفاق، والاطار المستمد من نموذج (هكثر -أولين). - توصيف نموذج الجاذبية: - 20 يعود مصطلح أو اصطلاح الجاذبية الى عام الطبيعة الثهير الفيزيائى اسحاق

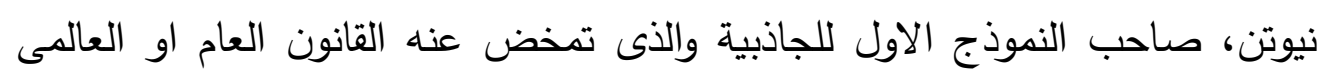

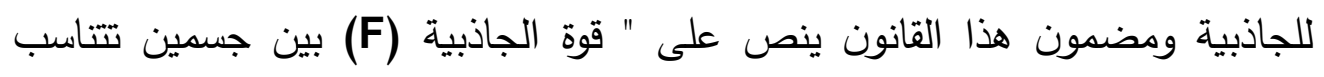
طرديا مع حاصل ضرب كتلتيهما (M مركزيهما، كالتالى: - ماصل فرديا

$$
\mathrm{F}=G \frac{M_{1} M_{2}}{D^{2}}
$$

$$
\text { ويعرف (G) بأنه ثابت الجاذبية العام. }
$$

يعبران عن الحجم الاقتصادى للدولتين، كما يقاس بالناتج المحلى الاجمالى M $_{2}$, M1 اللدولتين j, D الدسافة بالكيلو مترات أو الاميال بين الدولتين وهى مؤشر لتكتل التجارة. وفى عام 1999 قام جان تتبرجن بتطبيق قانون نيوتن فى مجال علم الاقتصاد وافترض الثكل العام التالى عام

$$
\mathrm{Y}_{\mathrm{ij}}=\mathrm{G} \frac{M_{J} M_{I}}{\text { Dist }_{i j}}
$$

وتمثل معادلة (Y)، صورة قانون نيوتن ويمن صياغتها فى الثكل الرياضى التالى:

$$
\begin{array}{r}
\mathrm{Y}_{\mathrm{ij}}=\mathrm{G} \frac{M_{J} M_{I}}{D i s t_{i j}^{2}}=\beta_{0} \frac{G D P_{i}^{\beta 1} G D P_{i}^{\beta 2}}{D s i t_{i j}^{\beta 3}} \\
\mathrm{Y}_{\mathrm{ij}}=\beta_{0}+G D P_{i}^{\beta 1} G D P_{j}^{\beta 2} D i s t_{i j}^{\beta 3}
\end{array}
$$


ومعادلة (ب)، هى معادلة أسية فى المعاملات، وبأخذ لوغاريتم الطرفين يتم تحويلها الى دالة خطية فى المعاملات على شكل دالة لوغاريتمية مزدوجة كالتالى:

$$
\operatorname{In} Y_{i j}=\beta_{0}+\beta_{1} \operatorname{In} G D P_{i}+\beta_{2} \operatorname{In}_{G D P_{j}}-\beta_{3} \text { In } D i s t_{i j}+\varepsilon_{i j}
$$

حيث: (عij): تمثل الخطأ العشوائى لمعادلة الانحدار •

ويمكن من المعادلة الخطية تفسير لوغاريتم تدفقات التجارة من صادرات أو

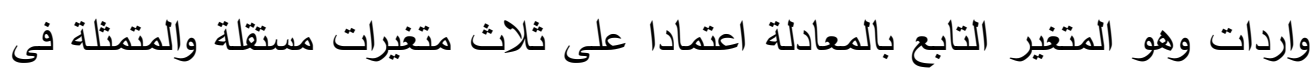
لوغاريتم حجم اقتصاد الدولة المصدرة، ولوغاريتم حجم اقتصاد الدولة المستوردة ولوغاريتم المسافة بينهما، ويمكن استخدام معلمات النموذج

لمرونة التدفقات التجارية لتفسير مستوى احجام اقتصاديات الدول أو المسافة بينها . والمعادلة رقم (ع) يطلق عليها نموذج الجاذبية الاساسى. واضاف lineman عام 197 عدد سكان الدولتين فى المعادلة (ع)، واطلق عليه نموذج الجاذبية المعدل وله عدد صور هى (r): $\operatorname{In} Y_{i j}=\beta_{0}+\beta_{1} \operatorname{In} G D P_{i}+\beta_{2} \operatorname{InGDP} P_{j}+\beta_{3} \operatorname{InPOp}_{i}+\beta_{4} \operatorname{InPOp}_{j}-\beta_{5} \operatorname{InDist}_{i j}+\varepsilon_{i j}$ $\operatorname{In} Y_{i j}=\beta_{0}+\beta_{1} \operatorname{In} p c G D P_{i}+\beta_{2} \operatorname{In} p c G D P_{i}-\beta_{3} \operatorname{InDIST}_{i j}+\varepsilon_{i j}$

كما يمكن إدخال متغيرات مستقلة أخرى فى النموذج وخاصة متغيرات صورية (D) $\operatorname{In} Y_{i j}=\beta_{0}+\beta_{1} \operatorname{In} G D P_{i}+\beta_{2} \operatorname{In} G D P_{j}-\beta_{3}{\operatorname{In} D i s t_{i j}}+\sum_{j=1}^{s} \alpha_{i j} D_{i j}+\varepsilon_{i j}$ حيث:

• التدفق التجارى (صادرات أو واردات) الدولة (ij

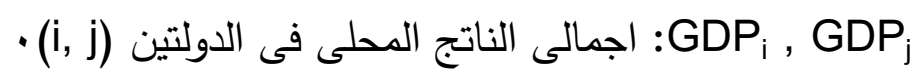
• (i, j) :Dist

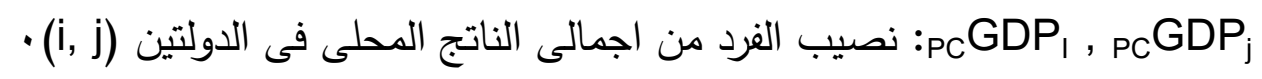
• عد السكان فى الدولتين (i, jop , POp 
متغير صورى يمثل (الحدود، اللغة، العملة المشتركة، الاتفاقيات : D

$$
\text { التجارية.......الخ) }
$$

ونظراً لان نموذج الجاذبية ذات صورة لوغاريتمية مزدوجة فان معاملات

الانحدار هى نفسها المرونات، وتتفق اشارات تلك المرونات مع المنطق الاقتصادى، لهوده

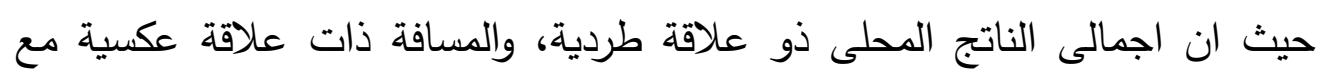
المتغير التابع (صادرات أو واردات)، ويعتمد نموذج الجاذبية أساساً على بيانات مقطعية تمثل عدد الدول وسلاسل زمنية تمثل السنوات للمتغيرات الاقتصادية للدول ولدئ

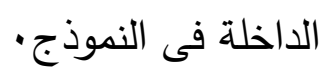

وغالباً ما توجه تقديرات نموذج الجاذبية فى مجال التجارة الخارجية مشكلة عدم

وجود تصدير او استيراد فى بعض السنوات بين بعض الدول، ولذلك يتم اعتبار قيم

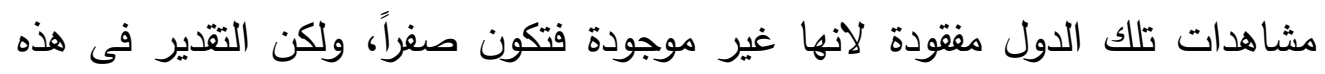
الحالة يعطى نتائج غير منطقية تماماً ولا يتبع التوزيع الطبيعى، لانه يتم التعامل مع دون

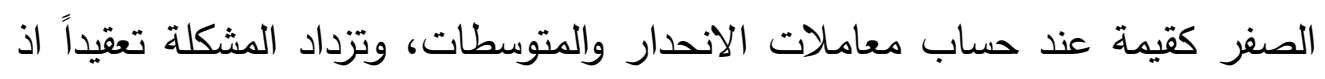
كان المتغير التابع لوغاريتمى، او يكون صافى التبادل التجارى بالسالب عند طرح صادرات الدولة (i)من واردات الدولة (j)، وهذا لا يمكن الحصول على لوغاريتم صفر

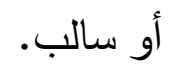

وللتغلب على تلك المشكلة يتم تحويل المتغير التابع الى صورة لوغاريتمية، ثم استبدال

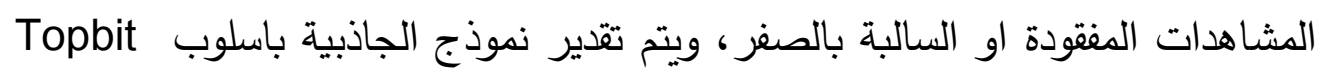

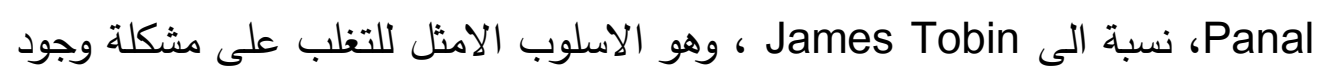
بيانات مفقودة او سالبة.

\section{- تطبيقات نموذج الجاذبية():}

التقدم الذى تم تحقيقه فى هيكلة نموذج الجاذبية يمكن تقسيمه الى ثلاث صيغ من خلالها يمكن تقدير عملية التدفق الاقتصادى بين بلد المنشأ وبلد المقصد، الاولى لهودج 
تقوم على جانب الطلب وهو نموذج (CEA/Amington)، والثانية تقوم على جانب العرض وهو نموذج (The Eaton-Kortum)، والثالثة مبنية على نموذج الاختيار المفصل، حيث يهتم كل عامل على حده كعامل المسافة او العمل او غيره. ويمكن الاثارة الى اربع استخدامات لتطبيق نموذج الجاذبية كما يلى: 1 التكلفة عند الحدود:

وفى ظل وجود تسهيلات للحدود المشتركة للتجارة الثنائية بين الدولتين (i,j)، فان نفس الحدود يمكن أن تكون عائقا للتجارة مع بقاء العوامل الاخرى ثابتة دون تغير ،

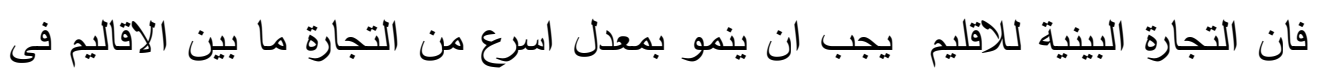
(i,j) r - تفسير أنماط التجارة:

يمكن تفسير أنماط التجارة باستخدام معادلة الجاذبية، وكذلك التجارة الكلية، والتجارة الثنائية فيما بين الصناعات، حيث تم وضع مؤشرات لها على مستوى الصناعة وهذه المؤشرات سواء كانت كلية او بمتوسط مرجح، تم تفسيرها باستخدام معادلة الجاذبية وكذلك نوع التجارة كطريقة بديلة لتحليل التجارة داخل الصناعات.

ب- تفسير أنماط التجارة:

حيث تم استخدام معادلة الجاذبية فى دولتين ا, واللتين وقعتا اتفاقية اقليمية ومتغيرين الاول هو Both in ومعناه ان الدولتين فى الاتفاقية، اما الثانى هو Both

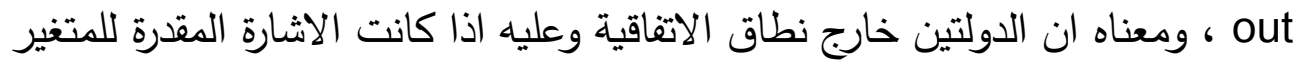
سالبة فان هناك تحويل للتجارة، ويتم اجراء هذا الاختبار لكى نصور التجارة In out المحتملة كنتيجة لانظمة التكامل الاقليمى. ع - تقدير التجارة المحتملة: 
يفسر نموذج الجاذبية للصادرات الثنائية بين دول العينة وذلك فى عملية

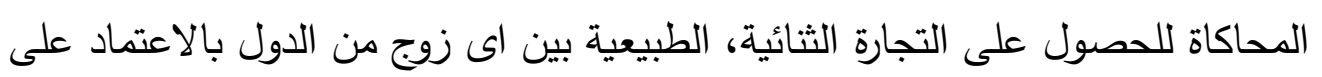

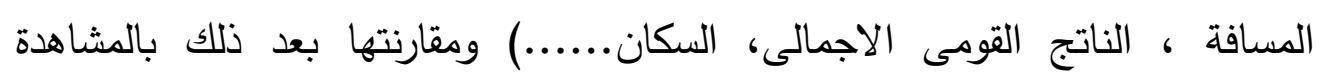
فنحصل على الصادرات الثنائية المحتملة. - أهداف دراسة التقدير القياسى لتدفق التجارة بين مصر ودول الكوميسا باستخدام

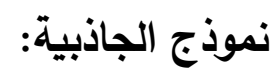
ا- دراسة تطور أهم المتغيرات الاقتصادية والتىى منها قيمة التدفق التجارى (الصادرات أو الواردات) بين مصر ودول الكوميسا، اجمالى الناتج المحلى لمصر ودول الكوميسا،

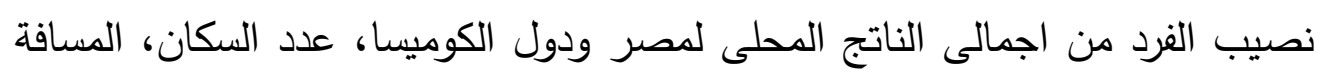
الجغرافية بين مصر وكل دولة من دول الكوميسا.

ץ- وضع نموذج قياسي لتدفق التجارة بين مصر ودول الكوميسا باستخدام نموذج الجاذبية لقياس اثار النموذج على التدفق التجارى بين مصر ودول لئسين الكوميسا. النتائج البحثية: فيما يلى استعراضا لنتائج تقدير نموذج الجاذبية للتجارة الخارجية الكلية

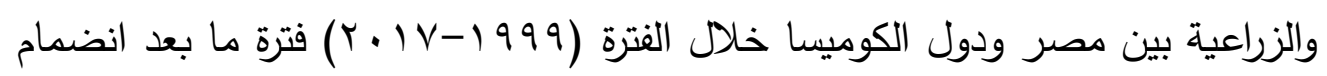
مصر لتكتل الكوميسا. اولاً: نتائج تقدير نموذج الجاذبية للتجارة الخارجية الكلية بين مصر ودول الكوميسا: تم تقدير نموذج الجاذبية للتجارة الخارجية الكلية بين مصر ودول الكوميسا فى حالتى الصادرات والواردات، وتجدر الاشارة ان عدد السنوات للفترة موضع الدراسة (9 (1) سنة فترة ما بعد انضمام مصر لتكتل الكوميسا، فى حين بلغ اجمالى عدد الدول

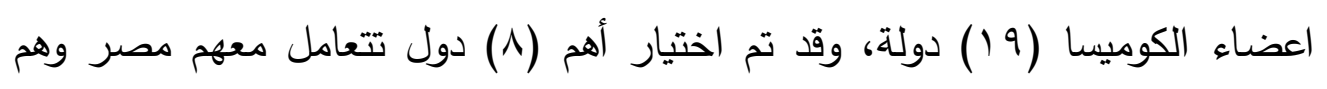

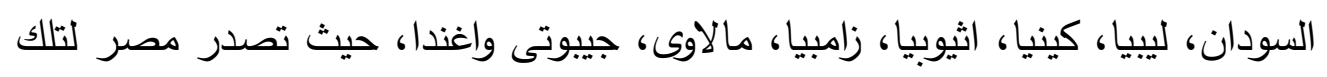

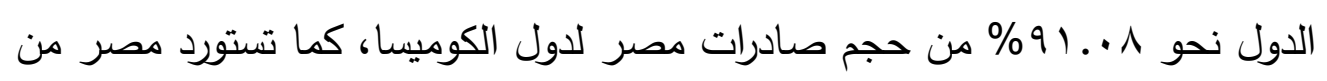


تلك الدول نحو اس.\%\% من حجم الواردات لمصر من دول الكوميسا خلال الفترة

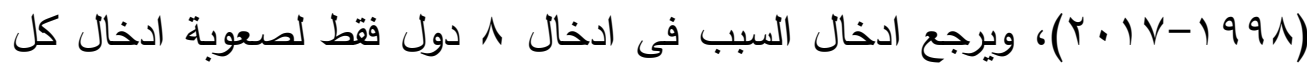
الدول فى تحليل النموذج. وتمكنت الدراسة من تقدير صورتين لنموذج الجاذبية فى وجود او عدم وجود متغيرات صورية: ا - نموذج الجاذبية الاساسى:

وهو يعكس الاثر الاجمالى لكل دولة على صادرات وواردات مصر ، ويشتمل على متغيرات اجمالى الناتج المحلى لمصر ودول الكوميسا والمسافة الجغرافية بين مصر وكل دولة. $\operatorname{In} Y_{i j}=\beta_{0}+\beta_{1} \operatorname{In} G D P_{i}+\beta_{2} \operatorname{In} G D P_{i}-\beta_{3} \operatorname{In} D I S T_{i j}+\varepsilon_{i j}$

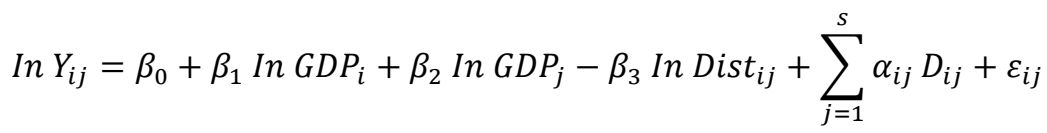

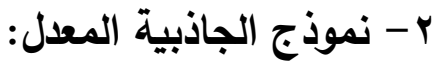

وهو يعكس الاثر الفردى لسكان كل دولة على صادرات وواردات مصر، ويشتمل على نصيب الفرد من اجمالى الناتج المحلى لمصر ودول الكوميسا والمسافة الجغرافية بين مصر وكل دولة. $\operatorname{In} Y_{i j}=\beta_{0}+\beta_{1} \operatorname{In} p c G D P_{i}+\beta_{2} \operatorname{In} p c G D P_{j}-\beta_{3} \operatorname{InDIST}_{i j}+\varepsilon_{i j}$ $\operatorname{In} Y_{i j}=\beta_{0}+\beta_{1} \operatorname{In} p c G D P_{i}+\beta_{2} \operatorname{In} p c G D P_{j}-\beta_{3} \operatorname{In} D i s t_{i j}+\sum_{j=1}^{s} \alpha_{i j} D_{i j}+\varepsilon_{i j}$

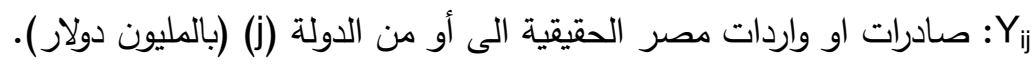
CDP1 CDP pcGDP

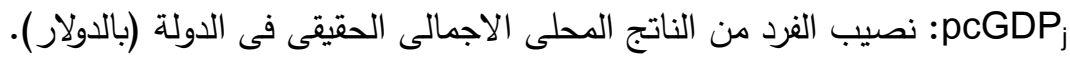


Distij

$$
\text { . (j) متغير صورى للدولة Dij }
$$

- نتائج نموذج الجاذبية الاساسى للصادرات المصرية لدول تكتل الكوميسا: تثير بيانات الجدول رقم ( (1)، الى نتائج نموذج الجاذبية الاساسي للصادرات

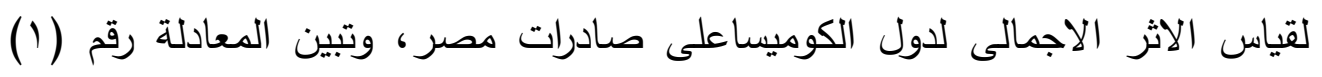
بالجدول سالف الذكر ، ان اجمالى الناتج المحلى لكل من مصر ودول الكوميسا الثمانية

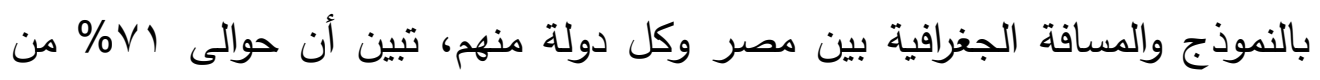

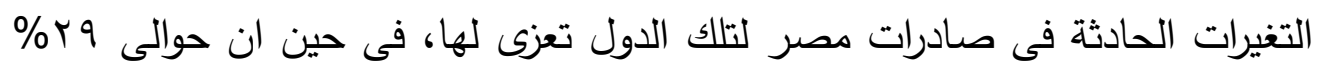

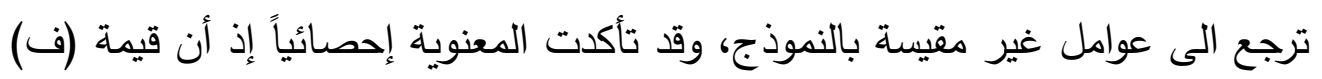

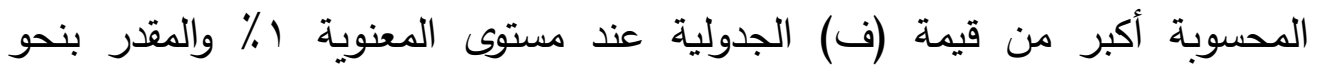

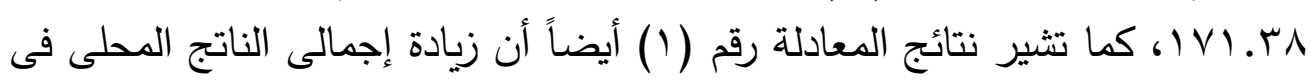

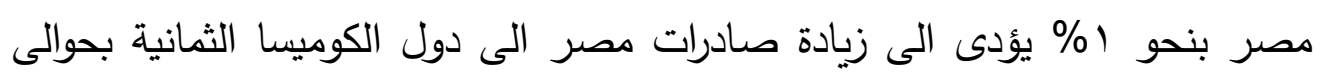

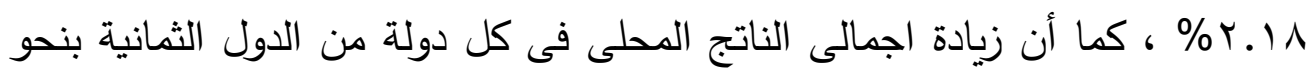

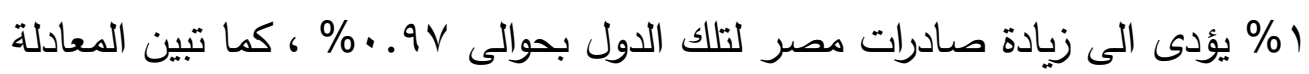

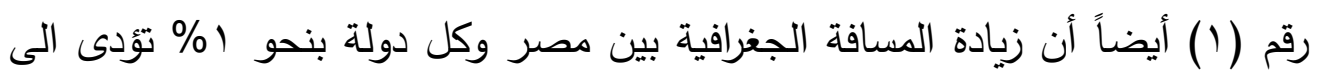

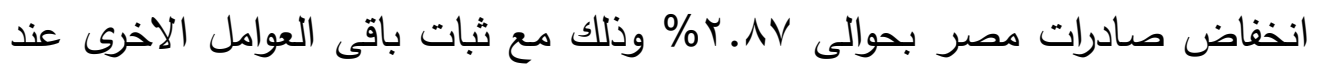
مستوى معين. 
جدول رقم (1): نتائج تقدير الجاذبية لصادرات مصر مع دول الكوميسا خلال الفترة (r. IV-199v)

\begin{tabular}{|c|c|c|}
\hline \multicolumn{2}{|c|}{ Export (In Yij) الصادرات } & \multirow[b]{2}{*}{ 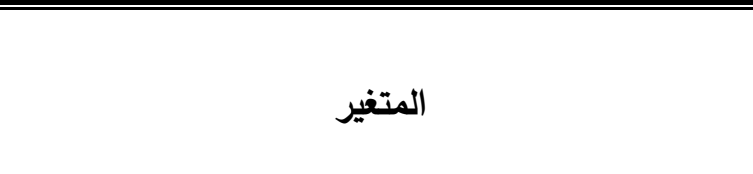 } \\
\hline $\begin{array}{c}\text { AGM } \\
(\curlyvee)\end{array}$ & $\begin{array}{c}\text { BGM } \\
(1)\end{array}$ & \\
\hline 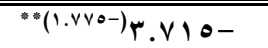 & 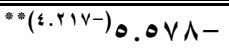 & (constant) \\
\hline & $" *(\Lambda . . \bullet \wedge)^{4.1 V q}$ & اجمالى الناتج المحلى لمصر \\
\hline & $*(1+. r 10) . .971$ & اجمالى الناتج المحلى لاول الكوميسا \\
\hline$\cdots(0 . r 4-)^{4}$.rYo- & $\begin{array}{l}-)^{-1} \text { Y.ATO- } \\
\cdots(1 . .194\end{array}$ & المسافة بين مصر ودول الكوميسا \\
\hline 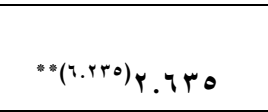 & & 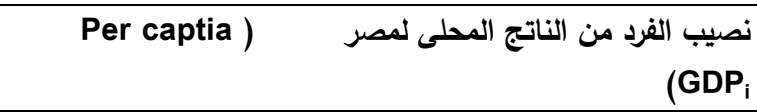 \\
\hline$*(1.901) \cdot .91$ & & Per captia ( نصيب الفرد من الناتج المحلى لدول الكوميسا \\
\hline 17. & 17. & $\mathbf{N}$ \\
\hline.$\cdot v \wedge$ &..$v 1$ & $\mathbf{R}^{2}$ \\
\hline$" 11.7 \varepsilon$ & "IVI.rA & F Test \\
\hline UV.AT & I.r..$\leqslant Y$ & LLF \\
\hline
\end{tabular}

الارقام بين القوسين وأسفل معاملات الانحدار تثير الى قيم (ت) المحسوبة.

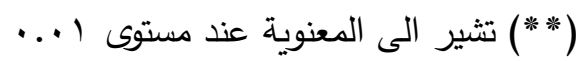

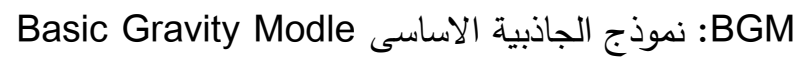

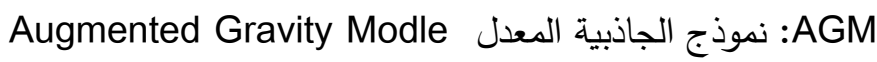

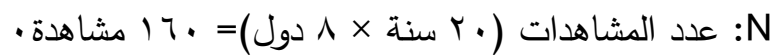
=R F Test LLF

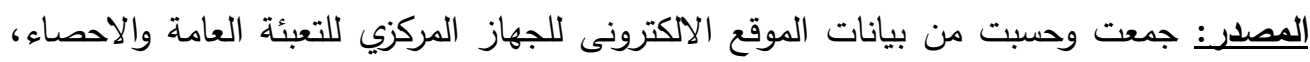
.$r \cdot 19$

ولبيان أثر كل دولة تم عمل (^) متغيرات صورية لدول الكوميسا الثمانية

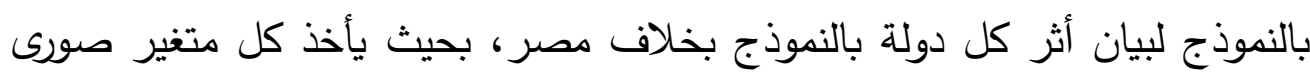
لسنوات كل دولة القيمة واحد، وصفر خلاف ذلك، كما قامت الدراسة باختبار الفروض 


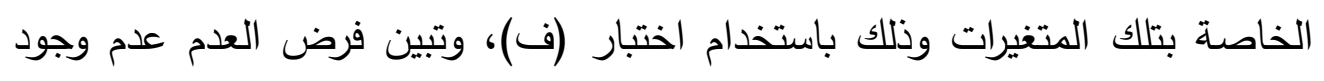

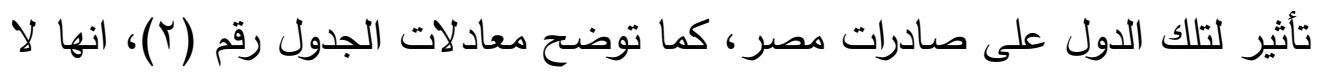
تحتوى على الحد الثابت منعا لحدوث ازدواج خطى كامل بين الحد الثابت والمتغيرات

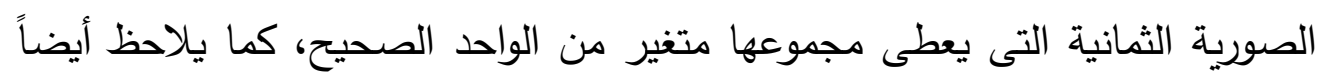

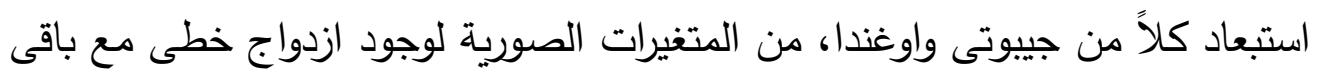

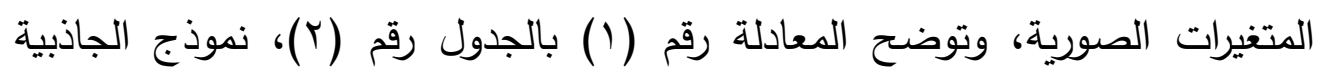

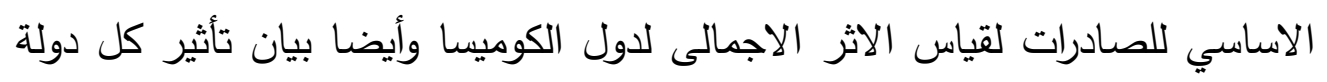

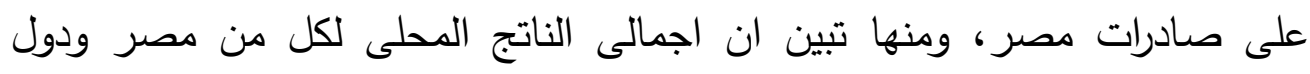

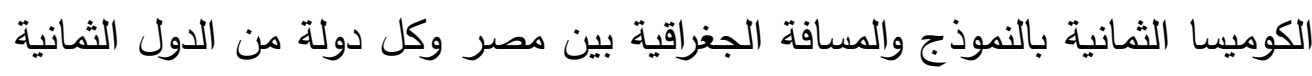

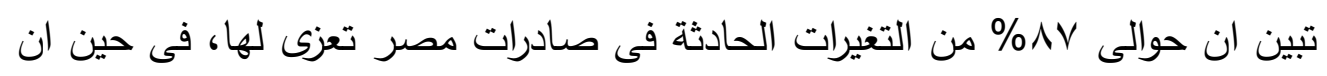

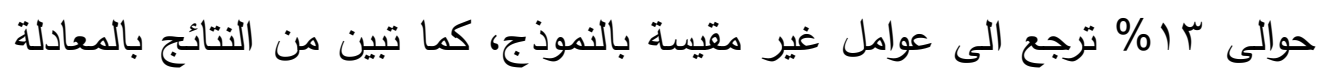

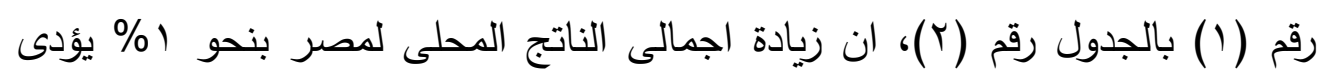

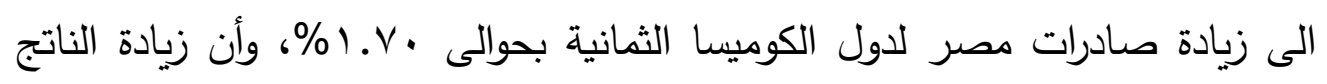

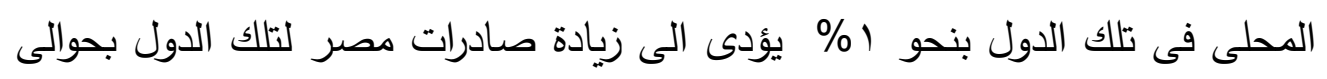

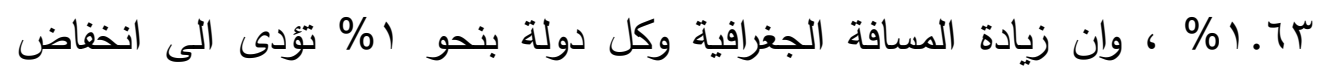

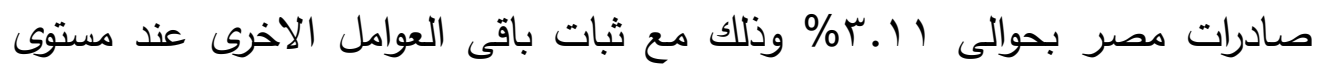

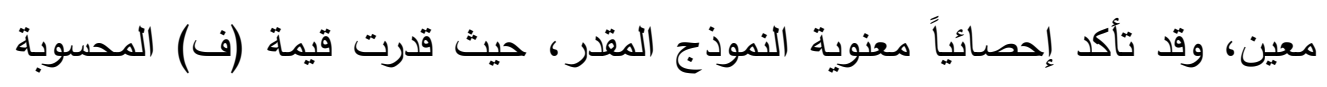

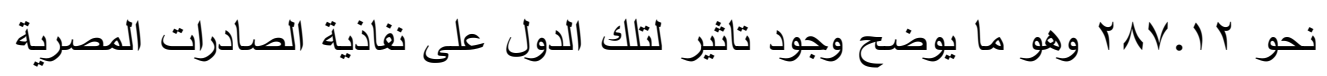

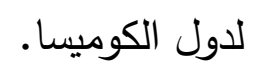

كما تبين من المعادلة رقم (1) بالجدول رقم (؟)، ان زيادة اجمالى الناتج

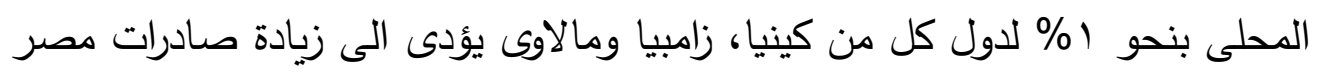

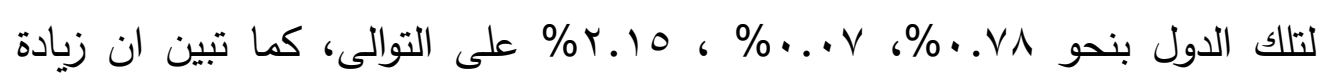

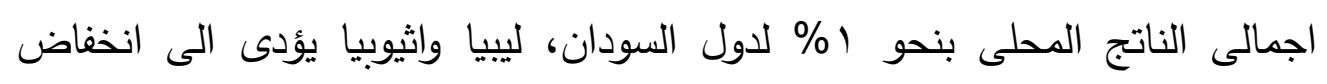

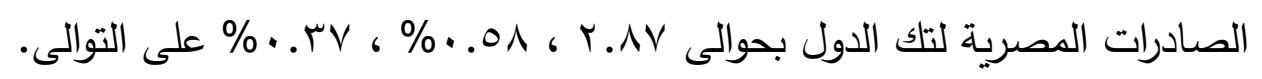




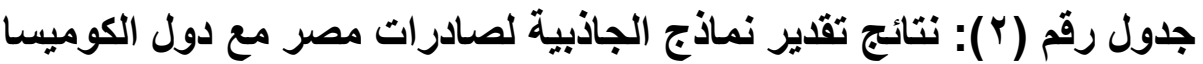

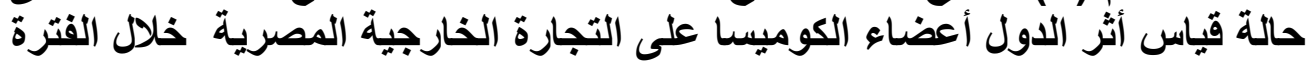
$(r+1 V-199 V)$

\begin{tabular}{|c|c|c|}
\hline \multicolumn{2}{|c|}{ Export (In Yij) الصادرات } & \multirow{2}{*}{ المتغير } \\
\hline AGM & BGM & \\
\hline & $* *(\wedge .1 \leqslant 0) 1.79 \wedge$ & اجمالى الناتج المحلى لمصر \\
\hline & 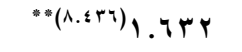 & اجمالى الناتج المحلى لدول الكوميسا \\
\hline 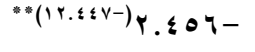 & $"(19.0 \leqslant r-\mu .1 .0-$ & المسافة بين مصر ودول الكوميسا \\
\hline "*(\&.MTV) 1. & & نصيب الفرد من الناتج المحلى لمصر \\
\hline$"(7.1 r \wedge) 1.7 \leq r$ & & نصيب الفرد من الناتج المحلى لاول الكوميسا (Per captia GDPi) \\
\hline "(0.rY-) & 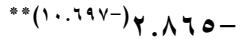 & Sudan \\
\hline$* *(r .0 \leqslant \Lambda) 1 . \leqslant(Y)$ & $" *(r .1 \leq \%-) . . \Delta \vee \leq-$ & Libya \\
\hline "*(0.\&11) r.or 9 & $* *(\cdot . \wedge \mid v)$. .V^r & Kenya \\
\hline$"(r .90 \Lambda-) . .1 \leq r-$ & $* "(r .79 \Lambda) \ldots \vee v 1$ & Zambia \\
\hline$" *(Y .0 \leqslant \Lambda) 1 . \leqslant Y 1$ & 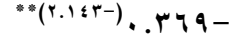 & Ethiopia \\
\hline$"(\ulcorner\cdot A \cdot 1-) 1 . \Gamma 11-$ & 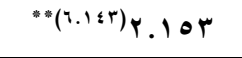 & Malawi \\
\hline ir. & ir. & $\mathbf{N}$ \\
\hline.$\wedge r$ &.$\wedge \mathrm{V}$ & $\mathbf{R}^{\mathbf{2}}$ \\
\hline$" *$ " $9 \vee .7 r$ & " r^V.Ir & F Test \\
\hline VT.O $\{-$ & $70.61-$ & LLF \\
\hline
\end{tabular}

الارقام بين القوسين وأسفل معاملات الانحدار تثير الى قيم (ت) المحسوبة •

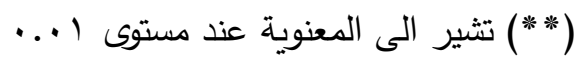

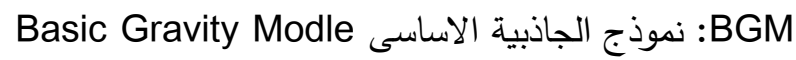

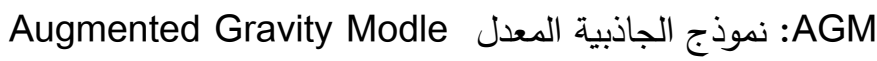

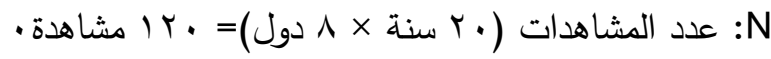
R2 F Test LLF المصدر: جمعت وحسبت من بيانات الموقع الآكترونى للجهاز المركزي للتعبئة العامة والاحصاء، .$r .19$ 


\section{- نتائج نموذج الجاذبية المعدل للصادرات المصرية لدول تكتل الكوميسا:} تثير بيانات الجدول رقم (1) بالمعادلة رقم (Y) قياس اجمالى الاثر الفردى

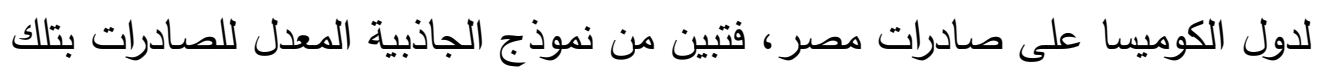

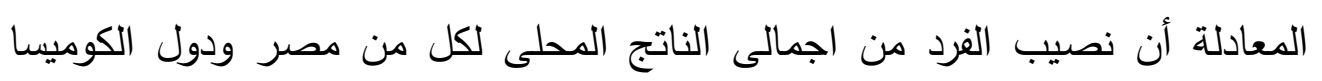

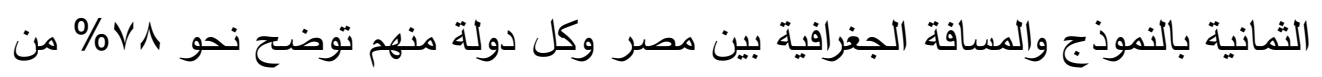

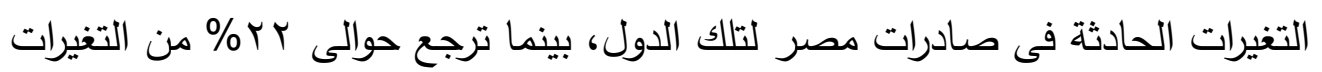
لعوامل اخرى غير مقيسة بالنموذج، وتبين النتائج أيضاً الى تأكد المعنوية الاحصائية

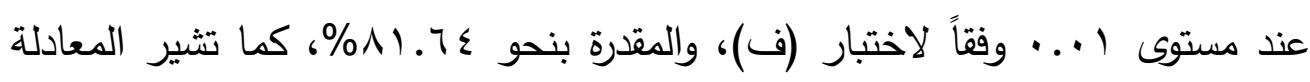

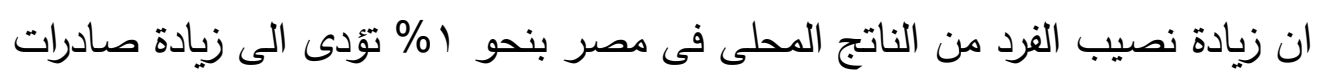

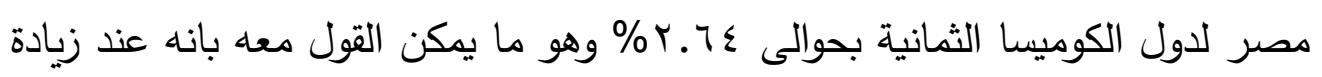

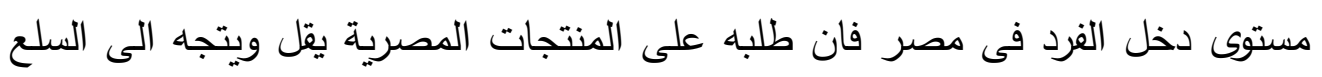
الاعلى جودة والتى يتم استيردها من الدول المتقدمة، وهو ما يتيح المجال لزيادة

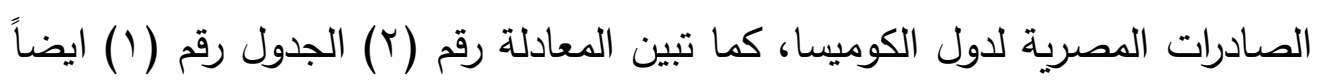

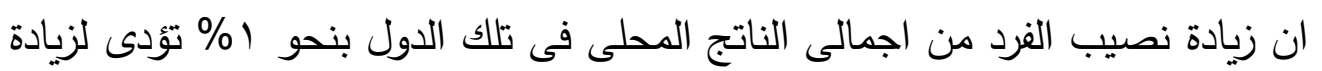

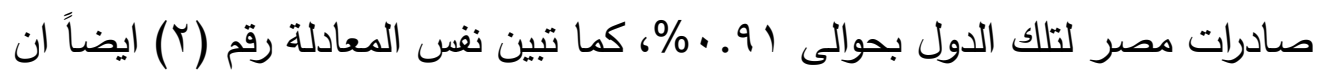

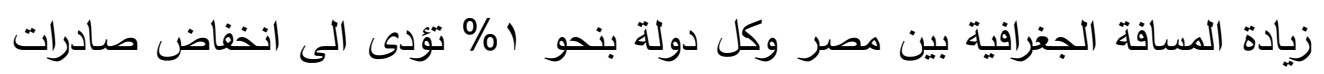

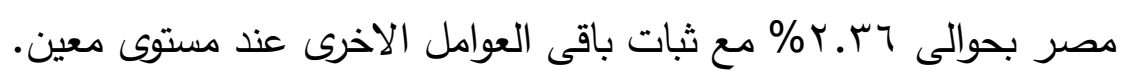
مما يشير الى انه عند زيادة دخل الفرد بدول الكوميسا، فان طلبه الاستيرادى

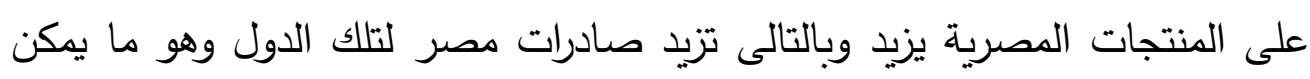

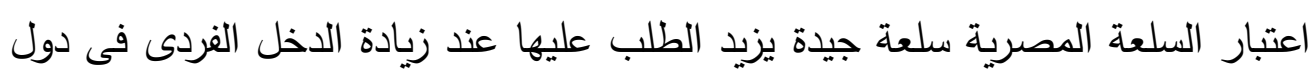
الكوميسا، ولقياس اجمالى الاثر الفردى بدول الكوميسا وبيان الاثر الفردى لكل دولة لـدلة

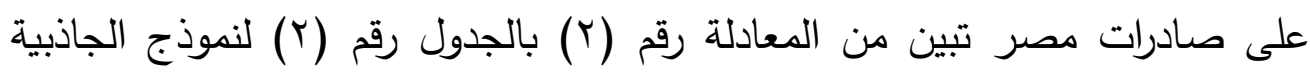
المعدل للصادرات ان نصيب الفرد من اجمالى الناتج المحلى لمصر ودول الكوميسا لئل

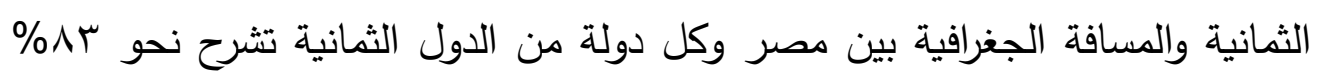

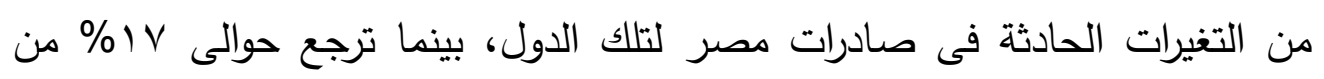
التغيرات لعوامل اخرى غير مقيسة بالنموذج. 
كما تثير ايضاً المعادلة رقم (Y) بالجدول رقم (Y)، ان زيادة نصيب الفرد من اجمالى الناتج المحلى فى مصر بنحو (\% يؤدى لزيادة صادرات مصر لدول الكوميسا

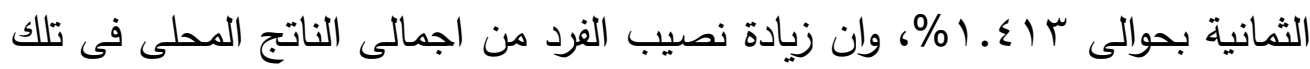

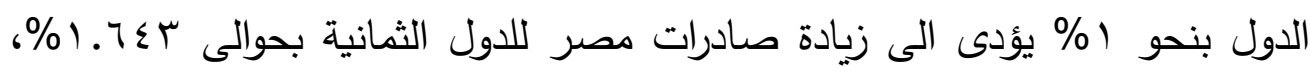

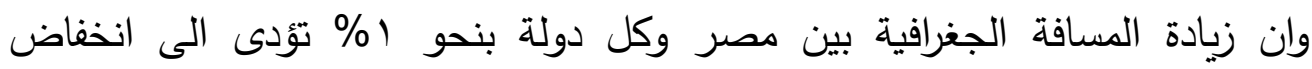

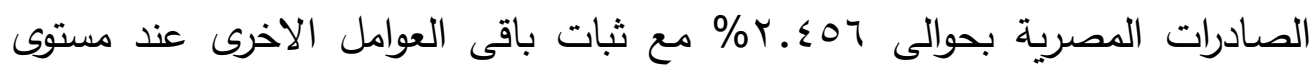

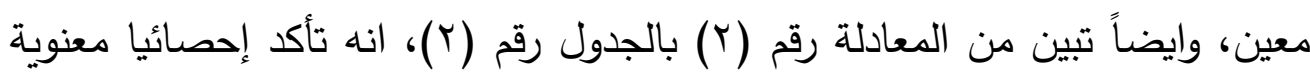
النموذج حيث أن قيمة (ف) المحسوبة لقياس الاثر الفردى لكل دولة على صادرات مصر والمقدرة بحوالى ب r. 19 1.

كما تبين وجود تأثير لمستوى الدخل الفردى للدول الثمانية على صادرات

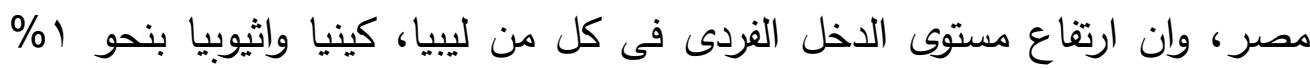

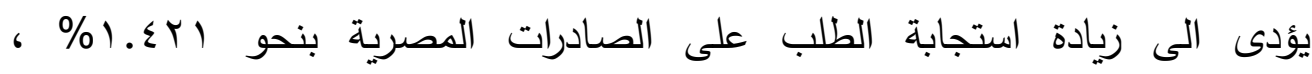

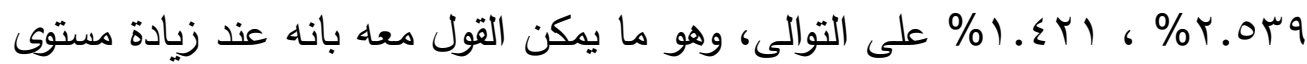
دخل الفرد بتلك الدول فان طلبه الاستيرادى على المنتجات المصرية يزيد وبالتالى تزيد صادرات مصر لتلك الدول، وهو ما يمكن اعتبار السلعة المصرية سلعة جيدة يزيد الطلب عليها عند زيادة مستوى الدخل الفردى فى كل من ليبيا، كينيا وأثيوبيا، وان

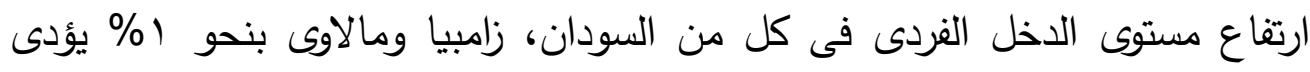

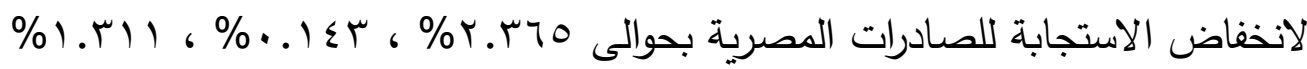
على التوالى، وقد يرجع ذلك الى انه عند زيادة مستوى دخل الفرد بتلك الدول فان طلبه الاستيرادى على المنتجات المصرية يقل، وبالتالى تتخفض صادرات مصر لتلك الدول وهو ما يمكن اعتبار السلعة المصرية سلعة رديئة يقل الطلب عليها عند زيادة مستوى الدخل الفردى فى كل من السودان، زامبيا ومالاوى ويلجا الى الاستيراد من دول أخرى. - نتائج نموذج الجاذبية الاساسى للواردات المصرية من دول الكوميسا: 
لقياس الأثر الاجمالى لدول الكوميسا على واردات مصر من خلال نموذج الإنج

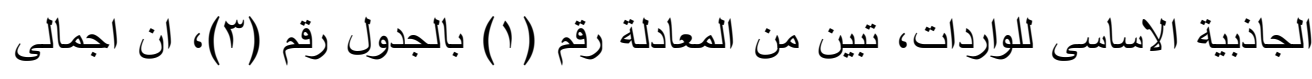

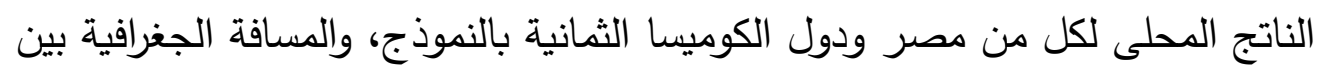

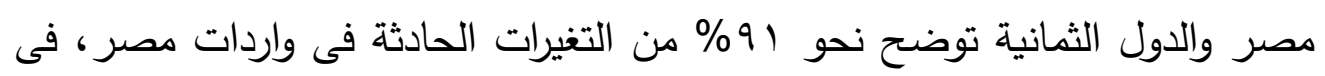

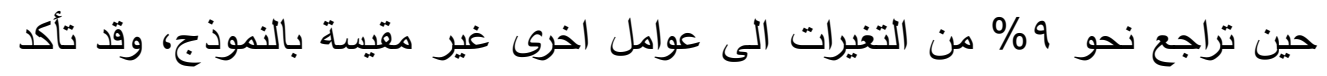

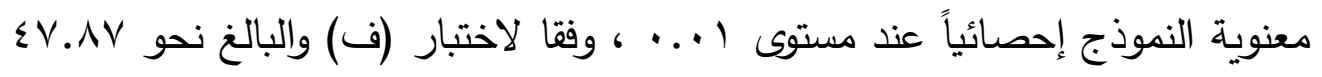

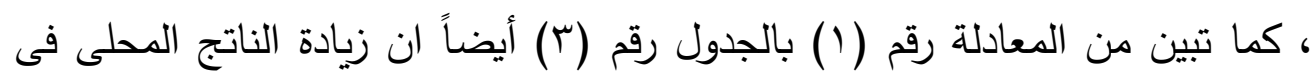

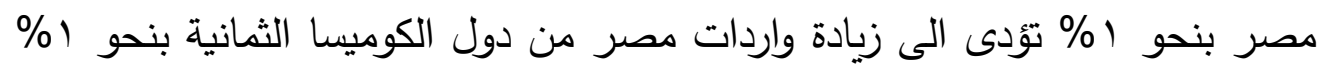

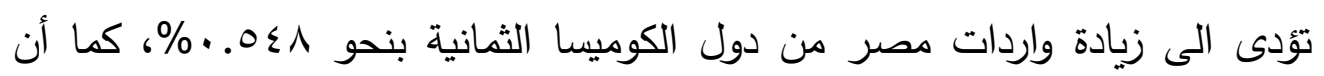

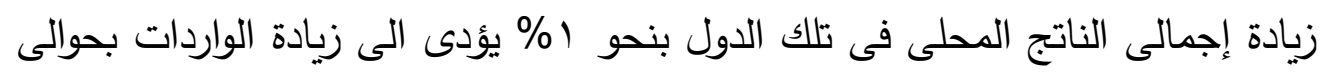

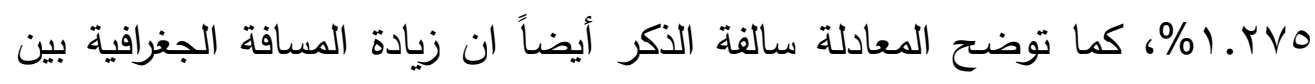

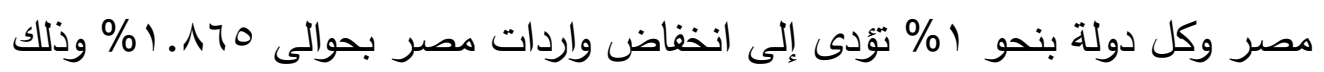
مع ثبات العوامل الأخرى عند مستوى معين.

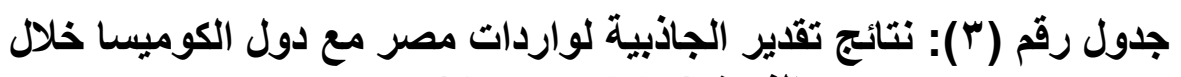
الفترة (r.lV-199V)

\begin{tabular}{|c|c|c|}
\hline \multicolumn{2}{|c|}{ Import (In Yij) الواردات } & \multirow{2}{*}{ المتغير } \\
\hline AGM & BGM & \\
\hline \multirow[t]{3}{*}{ "* } & 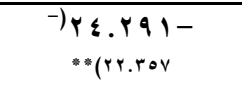 & ثابت المعادلة \\
\hline & $(\varepsilon . \leqslant 7) . .0 \leqslant \wedge$ & اجمالى الناتج المحلى لمصر \\
\hline & "*(1..sru)1.rVD & اجمالى الناتج المحلى لدول الكوميسا \\
\hline$" *(7.1 Y A-) 4.9 \vee \wedge-$ & $"(9.790-)) .1 .190-$ & المسافة بين مصر ودول الكوميسا \\
\hline$"(4 . \wedge \leqslant 0) . .07 \mathrm{~V}$ & & (Per captia GDP (Pصيب الفرد من الناتج المحلى لمصر \\
\hline$" *(9.1 r \wedge) 1 . \leq r V$ & & Per captia ( نصيب الفرد من الناتج المحلى لاول الكوميسا \\
\hline 19. & 19. & $\mathbf{N}$ \\
\hline$\cdot . \wedge r$ &. .91 & $\mathbf{R}^{2}$ \\
\hline "* ห.० & $" * V . \wedge V$ & F Test \\
\hline $1 \leq \Lambda .7 V$ & $1 \% 1.10$ & LLF \\
\hline
\end{tabular}

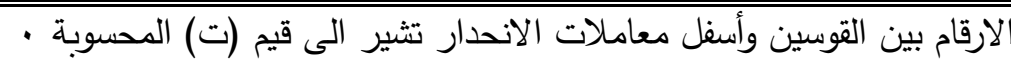

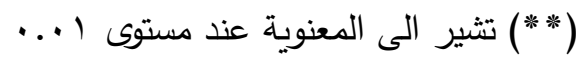
Basic Gravity Modle نموذج الجاذبية الاساسى عنى : 


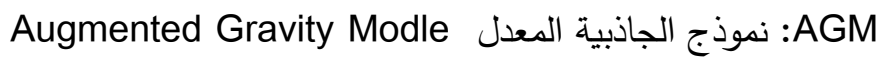

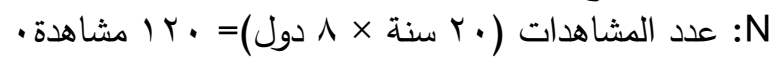
=R F Test LLF

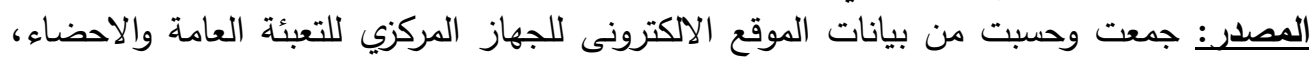
.r. 19

وتبين المعادلة رقم (1) بالجدول رقم (ع)، نتائج قياس الاثر الاجمالى لدول الكوميسا مع بيان تأثير كل دولة على واردات مصر ، حيث تأكدت المعنوية الاحصائية وفقا لقيمة (ف) المحسوبة والتى تقدر بنحو دو.09 ، كما تبين نتائج القياس بالمعادلة والجدول سالف الذكر، ان اجمالى الناتج المحلى لكل من مصر ودول الكوميسا الثمانية

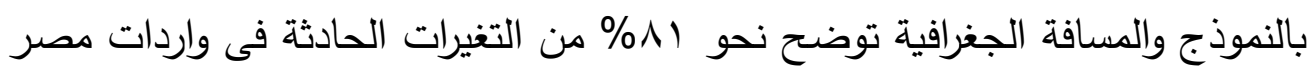
بين تلك الدول، فى حين ترجع حوالى 9 (1\% لعوامل اخرى غير مقيسة بالنموذج.

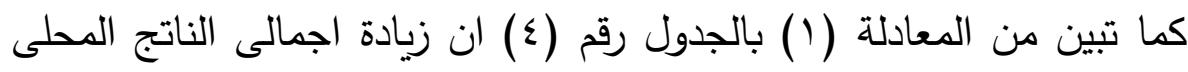
فى مصر بنحو 1\% يؤدى الى انخفاض واردات مصر من دول الكوميسا الثمانية بحوالى 19. 19. (19 ، كما تبين أيضا أن زيادة اجمالى الناتج المحلى فى كل دولة من

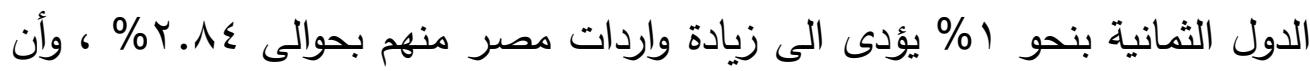
زيادة المسافة الجغرافية بين مصر وكل دولة بنحو ( ) تؤدى الى انخفاض واردات مصر بحوالى Y V9. . . \% وذلك مع ثبات باقى العوامل الاخرى عند مستوى معين، كما تأكد إحصائياً معنوية اختبار (ف) لوجود تأثير لتلك الدول على نفاذية صادراتها لمصر، وتبين ان زيادة اجمالى الناتج المحلى بنحو (\% الدولتى كينيا ومالاوى يؤدى

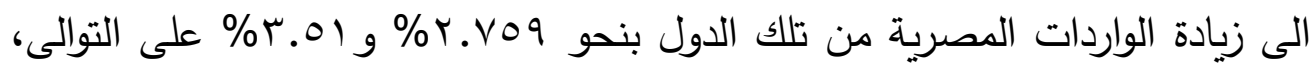

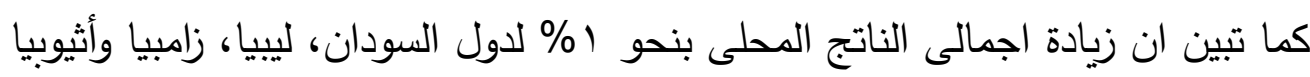

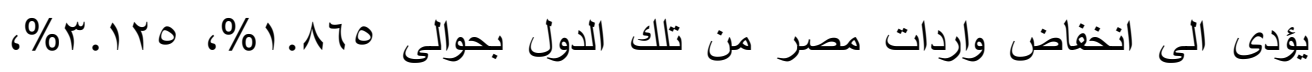

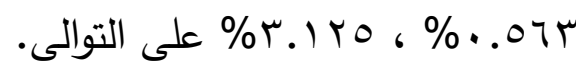

- نتائج نموذج الجاذبية المعدل للواردات المصرية من دول الكوميسا: 
تثير المعادلة رقم (Y)، بالجدول رقم (Y)، لقياس اجمالى الاثر الفردى لكل

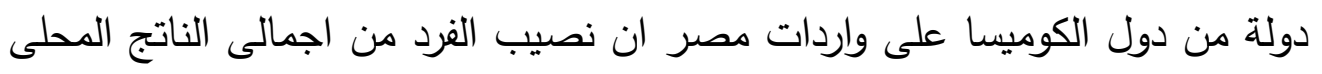

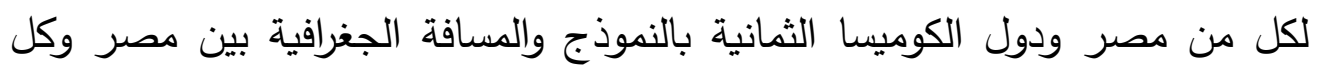

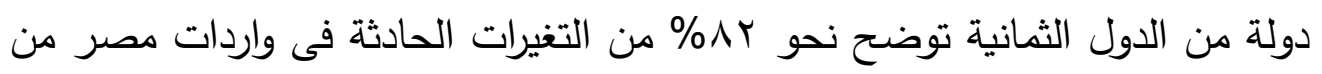

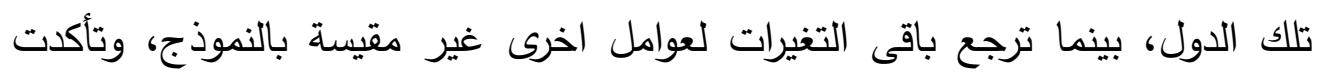

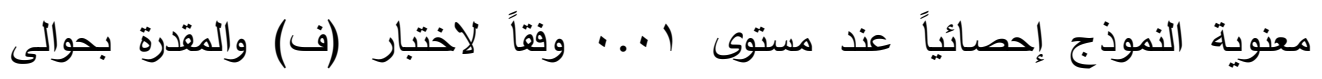
§.0.0،، كما تبين من المعادلة سالفة الذكر ان زيادة نصيب الفرد من اجمالى الناتج

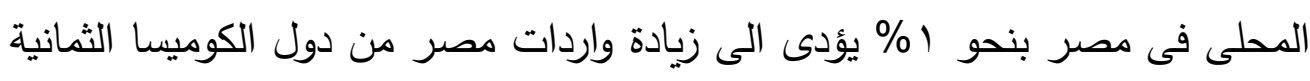

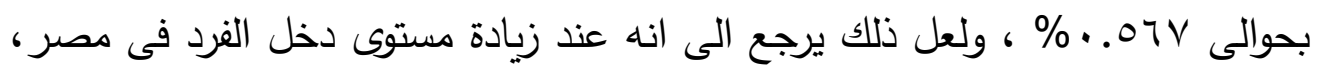

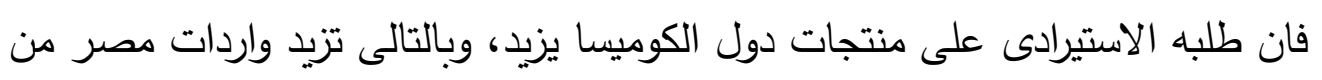

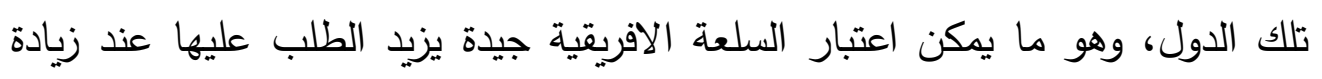

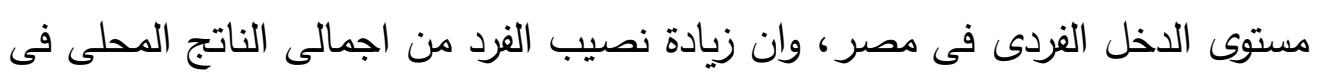

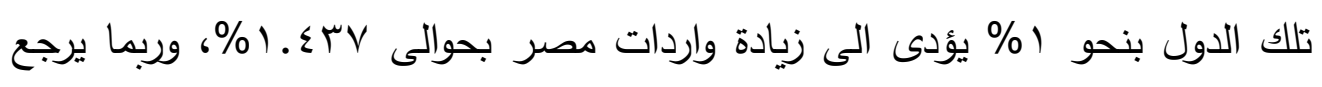

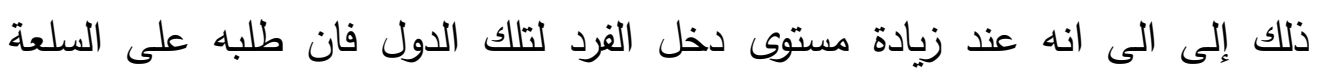

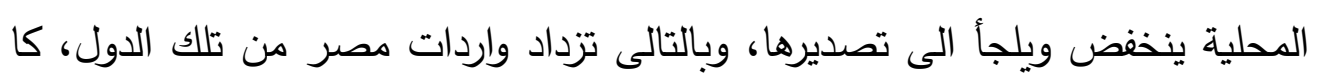

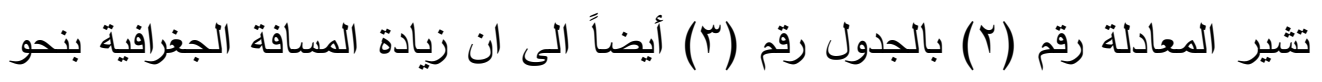

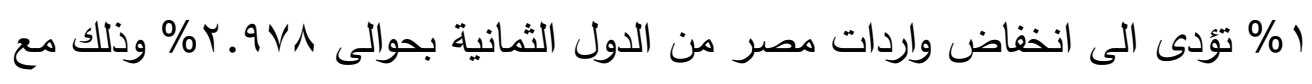
ثبات باقى العوامل الاخرى عند مستوى معين. ولقياس اجمالى الاثر الفردى بدول الكوميسا وبيان الاثر الفردى لكل دولة من

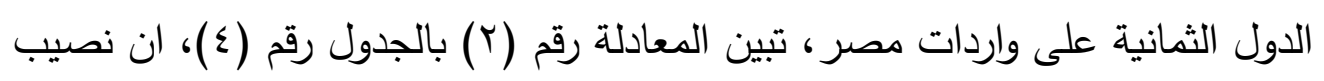

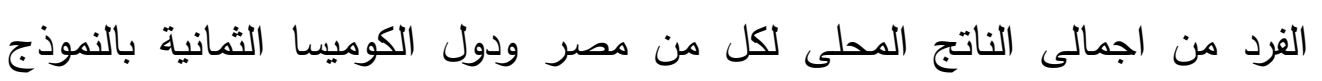

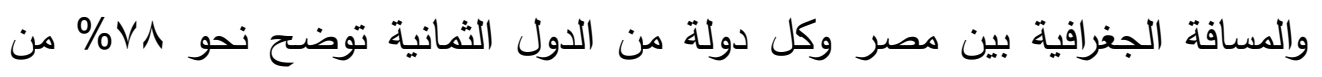

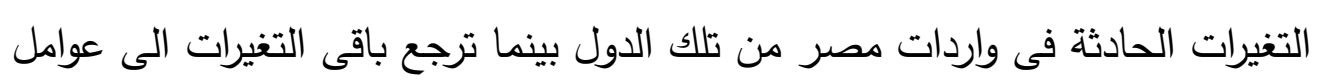

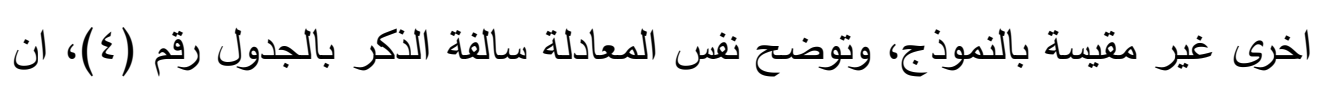

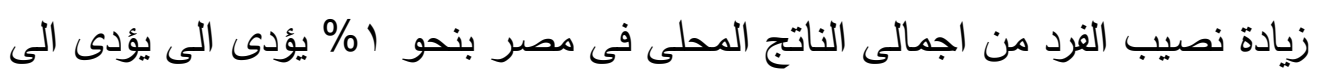


انخفاض الواردات بحوالى بـ9. • \% ، وان زيادة نصيب الفرد من اجمالى الناتج

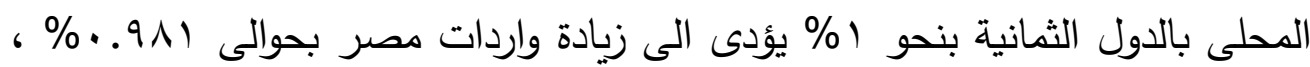
وان زيادة المسافة الجغرافية بين مصر وكل دولة بنحو إو بؤدى الى انخفاض

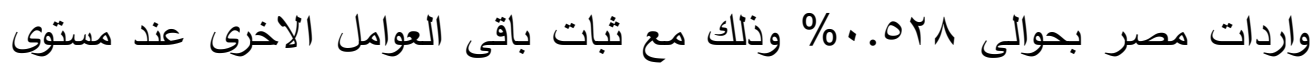

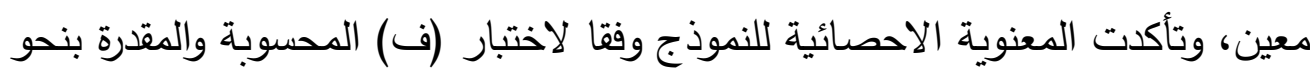
. $1.0 r$

وهو ما يتضح معه وجود تاثير لمستوى الدخل الفردى لتلك الدول على واردات مصر، حيث تبين ان ارتفاع مستوى الدخل الفردى فى كل من السودان، ليبيا، كينيا،

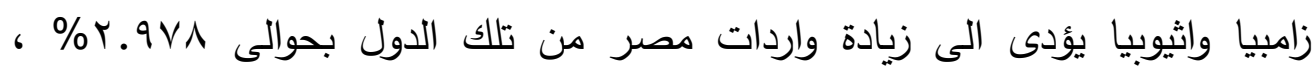

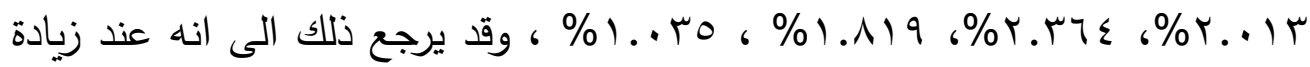
مستوى دخل الفرد بتلك الدول فان طلبه على السلعة المحلية ينخفض ويلجأ الى تصديرها وبالتالى تزداد واردات مصر من السودان، ليبيا، كينيا، زامبيا واثيوبيا، كما ليانه

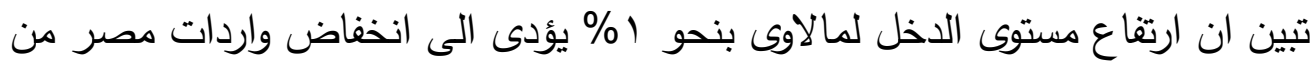

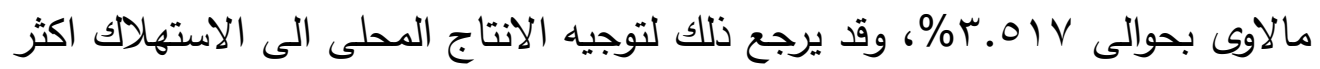
من التصدير عند ارتفاع مستوى الدخل الفردى لمالاوى. 


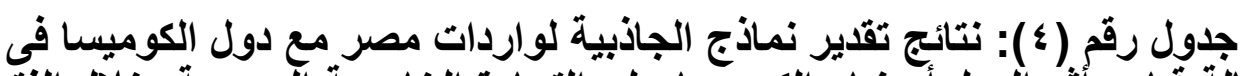

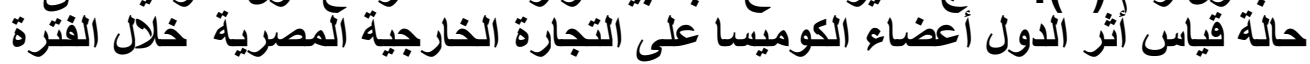

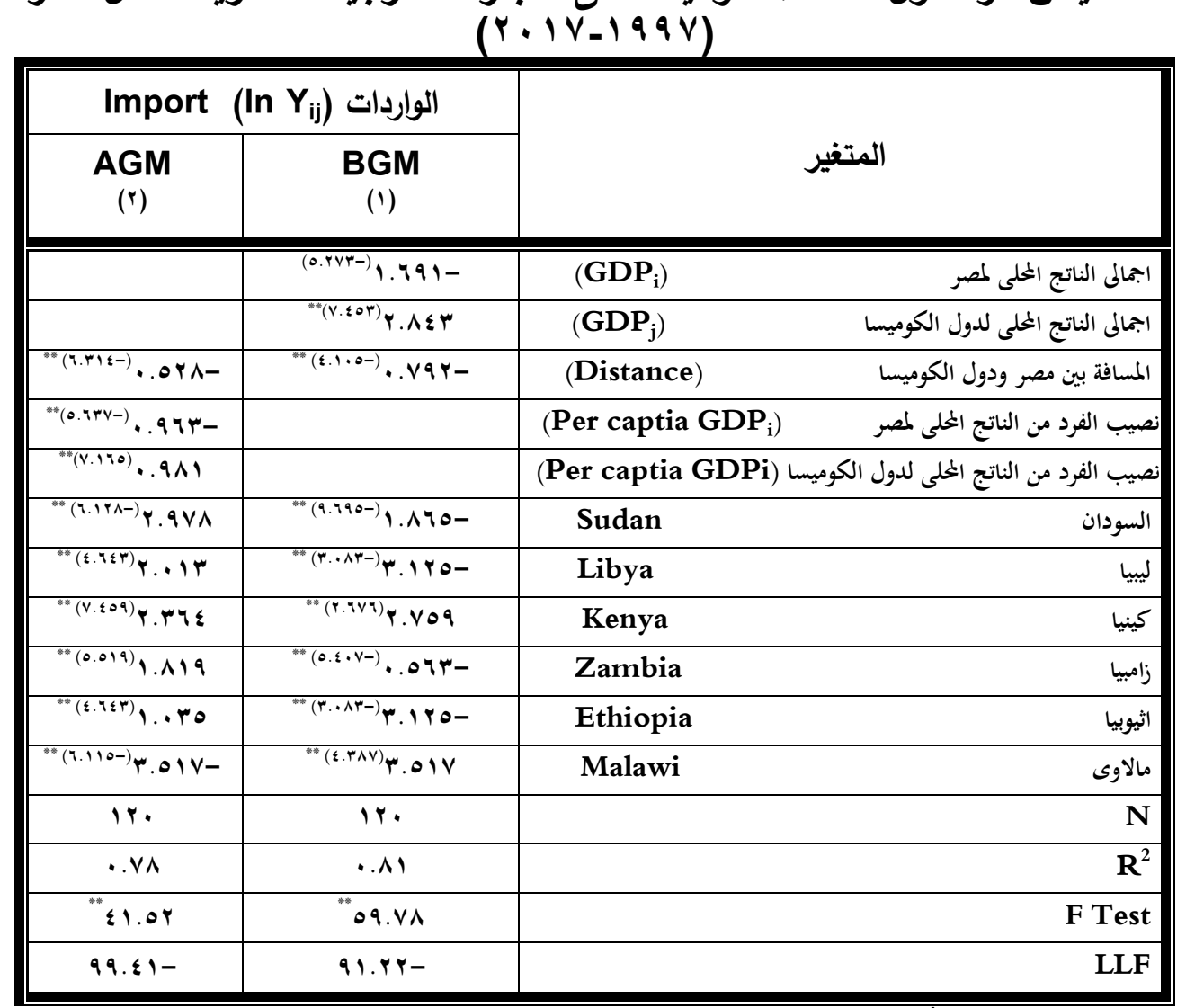
الارقام بين القوسين وأسفل معاملات الانحدار تثير الى قيم (ت) المحسوبة ·

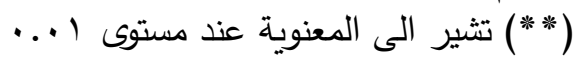

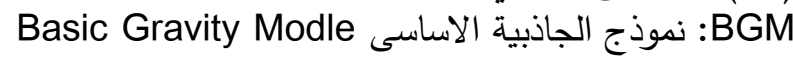
Augmented Gravity Modle نموذج الجاذبية المعدل

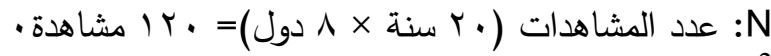
= معامل التحديد F Test LLF المصدر: جمعت وحسبت من بيانات الموقع الآكترونى للجهاز المركزي للتعبئة العامة والاحضاء، .$r \cdot 19$

ثانياً: تقدير نموذج الجاذبية للتجارة الخارجية الزراعية بين مصر ودول الكوميسا: فيما يلى استعراضاً لنتائج نموذج الجاذبية الاساسي والمعدل من الصادرات

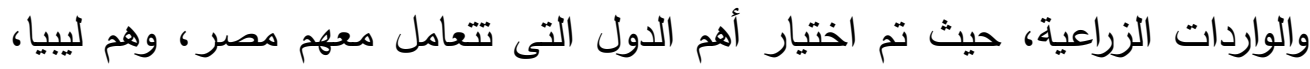




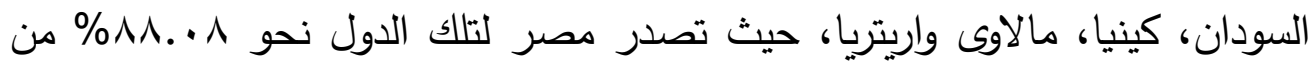

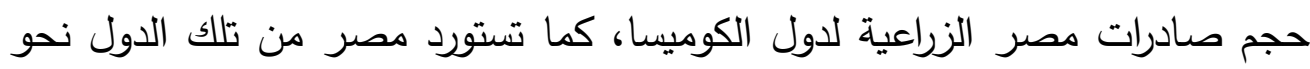

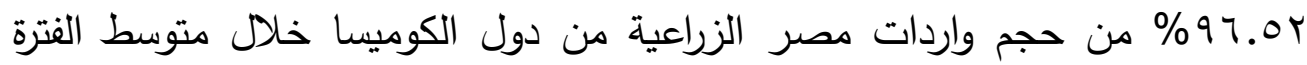
(Y . IV-199V)

- نتائج نموذج الجاذبية الاساسى للصادرات الزراعية المصرية لاول تكتل الكوميسا: تثير بيانات الجدول رقم (0)، الى نتائج نموذج الجاذبية الاساسي لصادرات

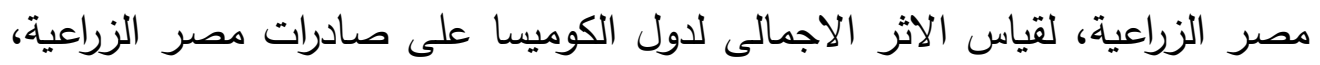

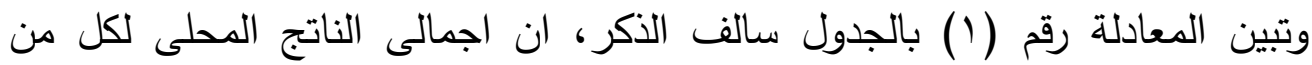

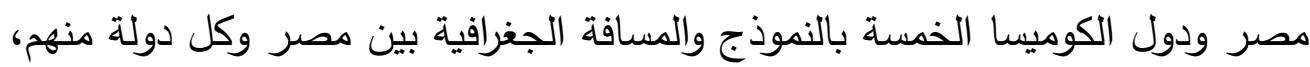
تبين أن حوالى ^^^\% من التغيرات الحادثة فى صادرات مصر الزراعية لتلك الدول

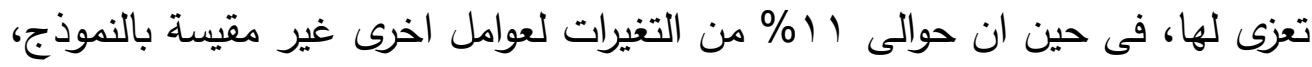

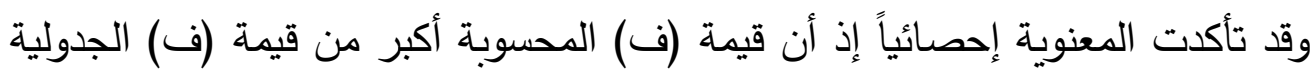

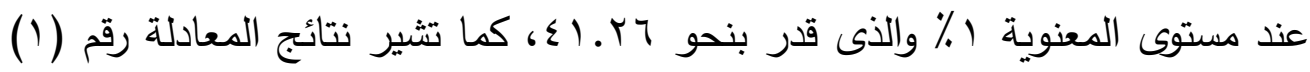

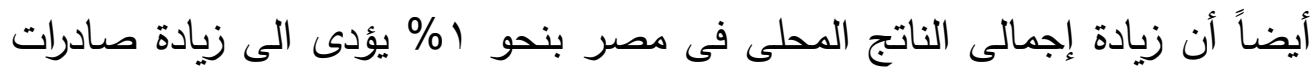

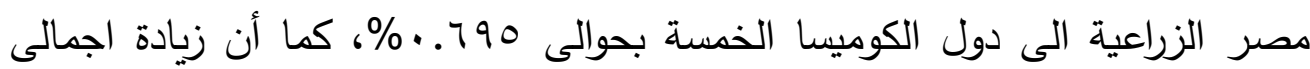

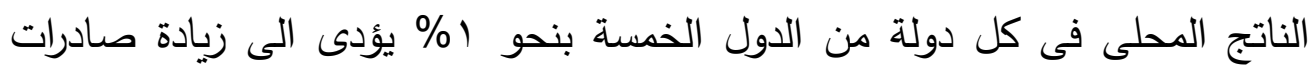

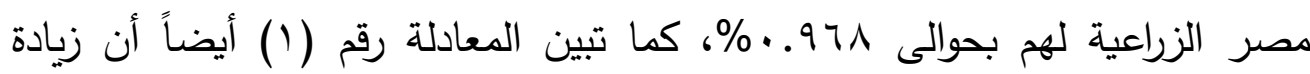

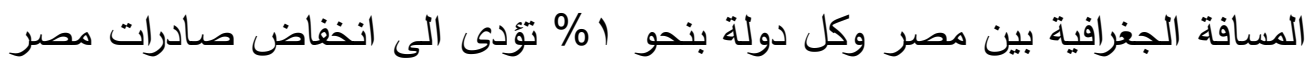

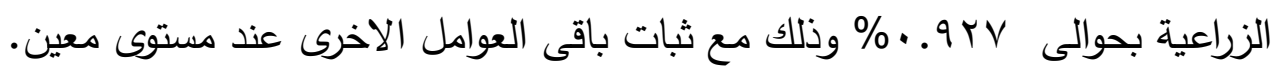
ولبيان أثر كل دولة تم عمل (0) متغيرات صورية لدول الكوميسا الخمسة بالنموذج - خلاف مصر - بحيث ياخذ كل متغير صورى (Dij) لسنوات كل دولة

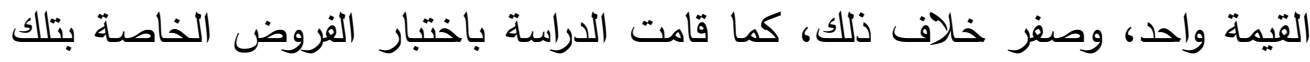
المتغيرات وذلك باستخدام اختبار (ف)، وتبين فرض العدم عدم وجود تأثير لتلك الدول

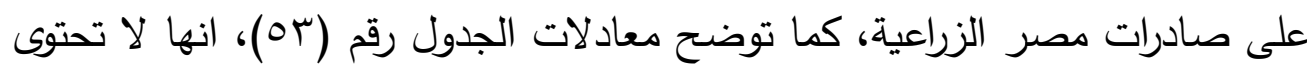
على الحد الثابت منعا لحدوث ازدواج خطى كامل بين الحد الثابت والمتغيرات الصورية لردات

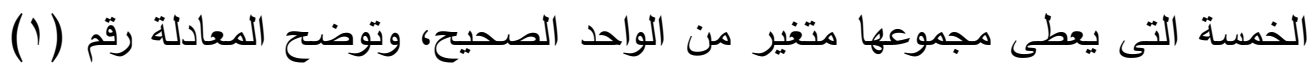

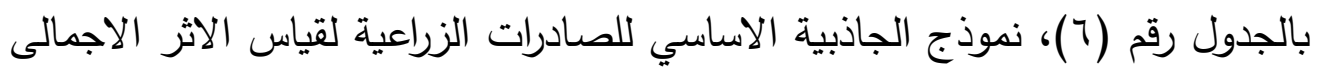


لدول الكوميسا وأيضا بيان تأثير كل دولة على صادرات مصر الزراعية، ومنها تبين ان

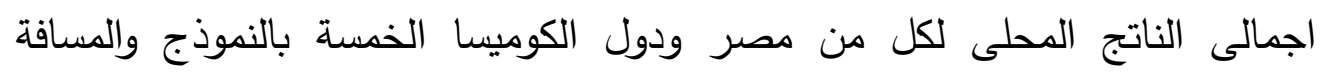

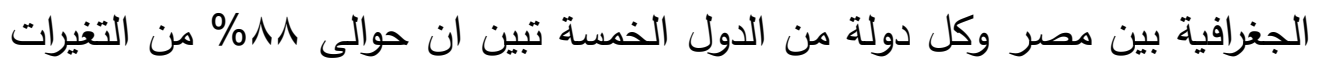

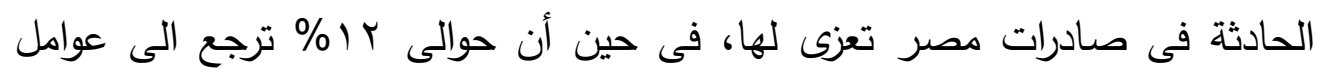
أخرى غير مقيسة بالنموذج. 
جدول رقم (0): نتائج تقدير نماذج الجاذبية لصادرات مصر الزراعية مع دول

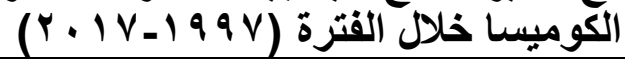

\begin{tabular}{|c|c|c|}
\hline \multicolumn{2}{|c|}{ Export (In Y Yij) الصادرات } & \multirow[b]{2}{*}{ المتغير } \\
\hline$\underset{(r)}{\text { AGM }}$ & $\begin{array}{c}\text { BGM } \\
(1)\end{array}$ & \\
\hline \multirow[t]{3}{*}{$" *(r . \wedge r \gamma-) \wedge . r \diamond \Sigma-$} & $" *(Y .9 r v-) \leq . .71 \wedge-$ & $\begin{array}{r}\text { ثابت المعادلة } \\
\text { (constant) }\end{array}$ \\
\hline & $* "(4 . Y \neg \wedge) . .790$ & $\begin{array}{r}\text { اجمالى الناتج المحلى لمصر } \\
\left(G D P_{i}\right)\end{array}$ \\
\hline & $* *(|r . r| 0) . .971$ & $\begin{array}{r}\text { اجمالى الناتج المحلى لدول الكوميسا } \\
\text { (GDP })\end{array}$ \\
\hline 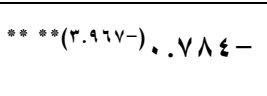 & $* "(r .79 \leqslant-) . .9 r v-$ & $\begin{array}{r}\text { المسافة بين مصر ودول الكوميسا } \\
\text { (Distance) }\end{array}$ \\
\hline$*(r .4 r \varepsilon) 1 . . r q$ & & 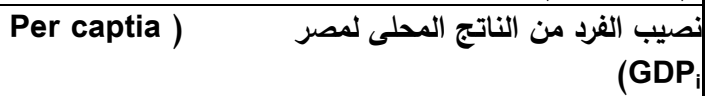 \\
\hline "*(๕.97V) 1. Y Y V & & Per captia ) نصيب الفرد من الناتج المحلى لاول الكوميسا (GDPi \\
\hline $1 \ldots$ & $1 \ldots$ & $\mathbf{N}$ \\
\hline..$\wedge r$ &. .19 & $\mathbf{R}^{2}$ \\
\hline$r \leq .09$ & $\leqslant 1 . Y 4$ & F Test \\
\hline 90.49 & $1.1 .14-$ & LLF \\
\hline
\end{tabular}

الارقام بين القوسين وأسفل معاملات الانحدار تثير الى قيم (ت) المحسوبة.

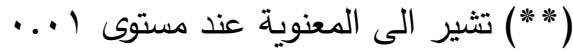

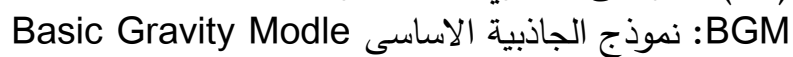

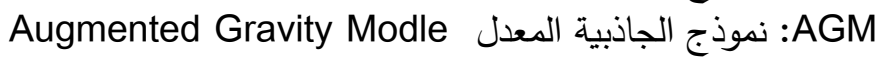

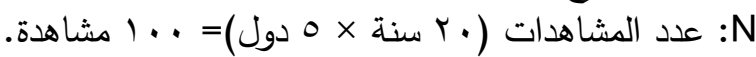
S معامل التحديد

F Test LLF المصدر: جمعت وحسبت من بيانات الموقع الالكترونى للجهاز المركزي للتعبئة العامة والاحصاء،

$$
\text { r.r.19 }
$$

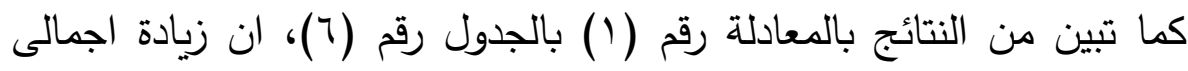

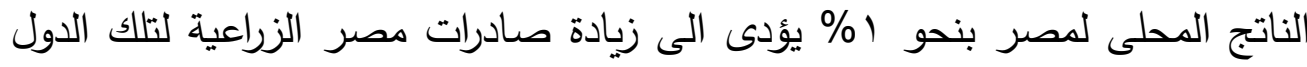

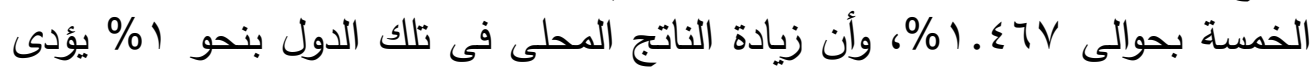

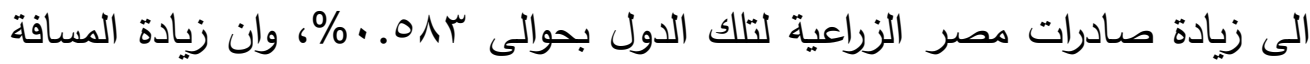

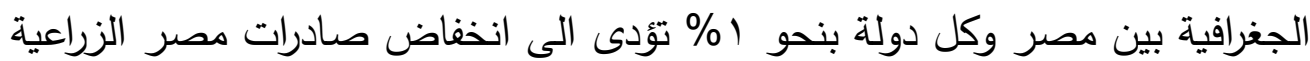

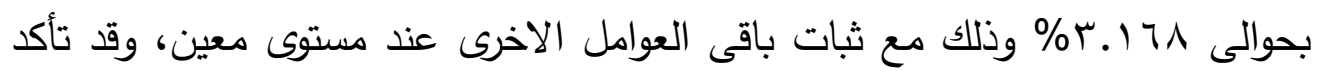




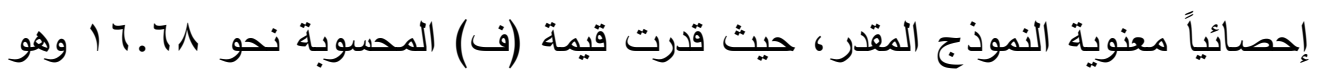
ما يوضح وجود تاثير لتلك الدول الخمسة على نفاذية الصادرات الزراعية بمصر لدول

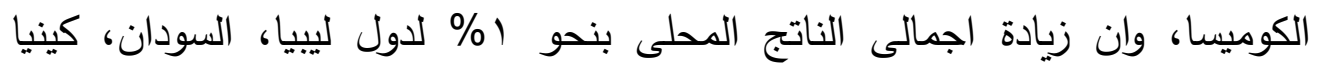

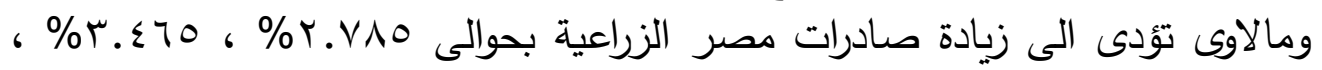

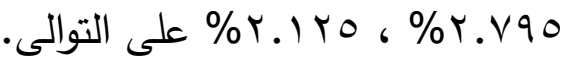

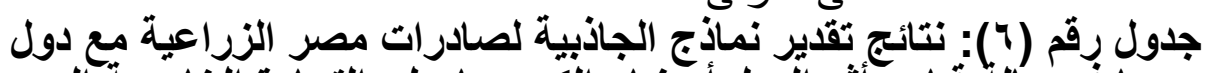

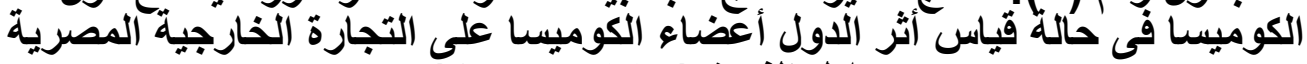

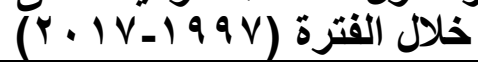

\begin{tabular}{|c|c|c|}
\hline \multicolumn{2}{|c|}{ Export (In Yij) الصادرات } & \multirow[b]{2}{*}{ 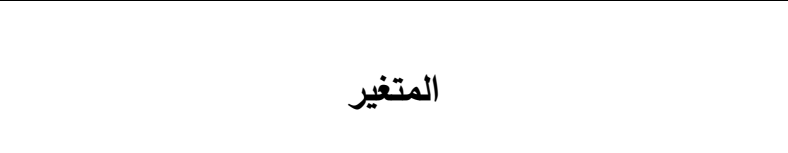 } \\
\hline \multirow[t]{3}{*}{$\begin{array}{c}\text { AGM } \\
(r)\end{array}$} & $\begin{array}{c}\text { BGM } \\
\text { (1) }\end{array}$ & \\
\hline & 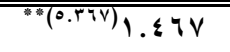 & اجمالى الناتج المحلى لمصر \\
\hline & $" *\left(\xi . Y T^{\circ}\right)$. .OAY & اجمالى الناتج المحلى لدول الكوميسا \\
\hline$" *(Y .97 V-)$ Y.VQ $9 \varepsilon-$ & $"(0 . r 9 \xi-)^{4.17 \Lambda-}$ & المسافة بين مصر ودول الكوميسا \\
\hline$" *(r .9 r V) 1 . \Lambda Y V$ & & نصيب الفرد من الناتج المحلى لمصر \\
\hline$" *(\xi .17 \lambda), . V \leq 0$ & & نصيب الفرد من الناتج المحلى لدول الكوميسا (Per captia GDPi) \\
\hline$*(0 . . Y Y)$. VOr & 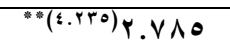 & ليبيا \\
\hline$" *(7.790) 1.719$ & $" *(\$ .94 \Lambda) \% . \$ 40$ & Sudan \\
\hline$"(r . Y 09) 1 . r 4 \Lambda$ & $" *(0.4 Y V) Y . \vee 90$ & Kenya \\
\hline- & "* (r.7QA) Y.IYO & Malawi \\
\hline$"(7.1 \times 0) 1.07 \mathrm{~V}-$ & - & Eritrea \\
\hline $1 \ldots$ & $1 \ldots$ & $\mathbf{N}$ \\
\hline.$\wedge \mathrm{V}$ & $\cdot . \wedge \wedge$ & $\mathbf{R}^{2}$ \\
\hline "17.rV & .17 .71 & F Test \\
\hline$\vee q . r v-$ & $71.1 V-$ & LLF \\
\hline
\end{tabular}

الارقام بين القوسين وأسفل معاملات الانحدار تشير الى قيم (ت) المحسوبة.

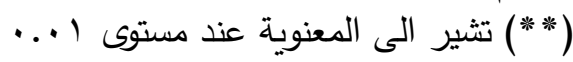

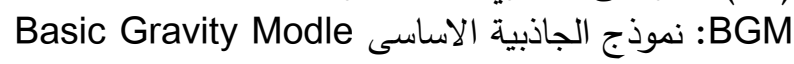

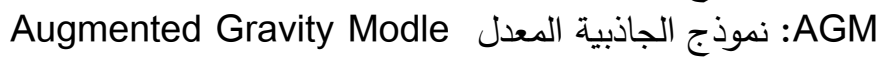

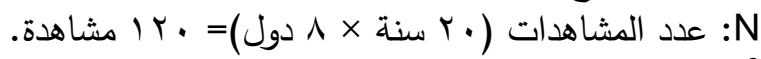
=R معامل التحديد اللوغاريتمي المصدر: جمعت وحسبت من بيانات الموقع الاكترونى للجهاز المركزي للتعبئة العامة والإحصاء، 
- نتائج نموذج الجاذبية المعدل للصادرات الزراعية المصرية لدول تكتل الكوميسا: تثير بيانات الجدول رقم (0) بالمعادلة رقم (Y) قياس اجمالى الاثر الفردى لدول الكوميسا على صادرات مصر الزراعية، فتبين من نموذج الجاذبية المعدل

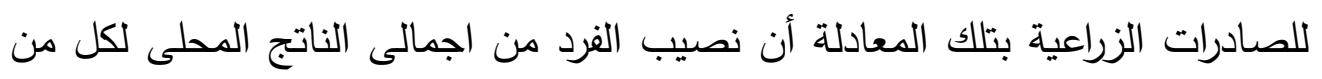

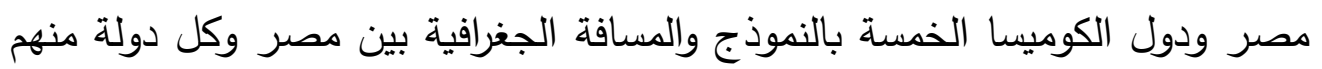

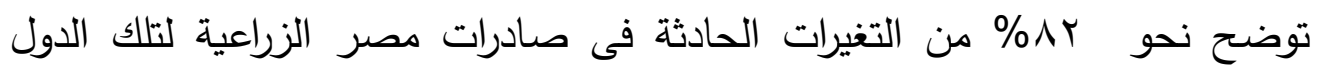

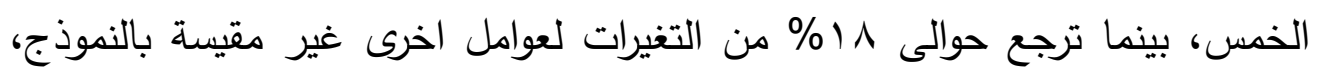

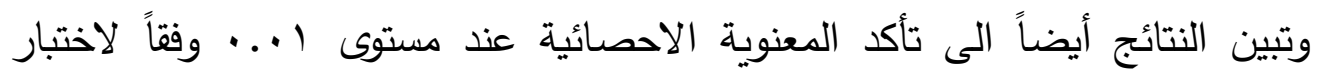

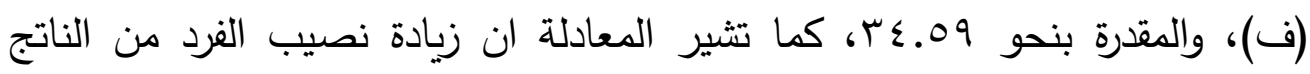
المحلى فى مصر بنحو (\% بؤدى الى زيادة صادرات مصر الزراعية لدول الكوميسا

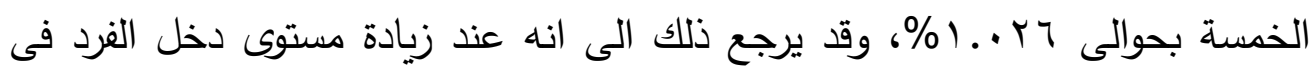

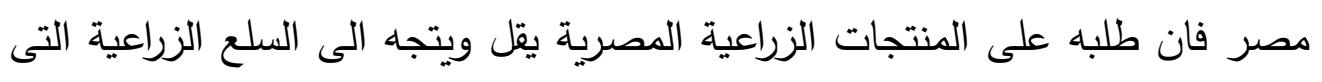

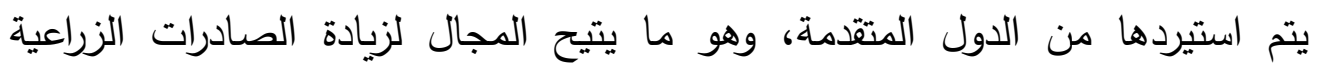

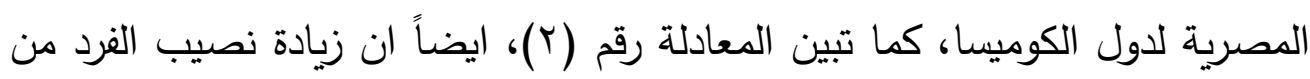

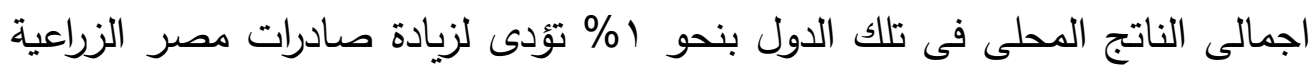

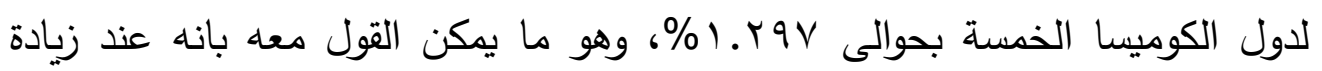
مستوى دخل الفرد بدول الكوميسا، فان طلبه الاستيرادى على المنتجات الزبل الزراعية

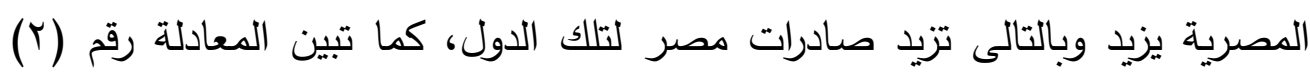

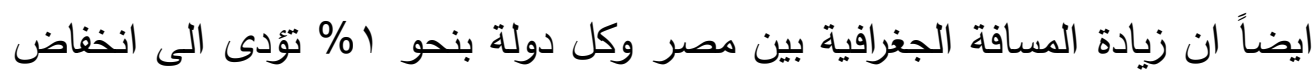

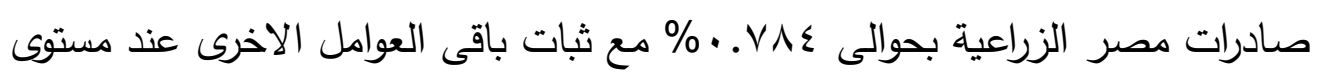
معين.

ولقياس أجمالى الأثر الفردى بدول الكوميسا مع بيان الاثر الفردى لكل دولة

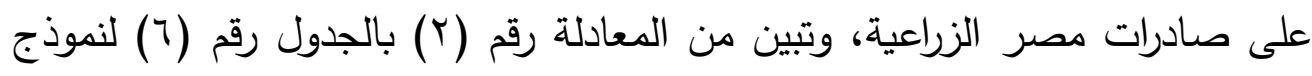
الجاذبية المعدل للصادرات الزراعية المصرية ان نصيب الفئ من الفرد من اجمالى الناتج

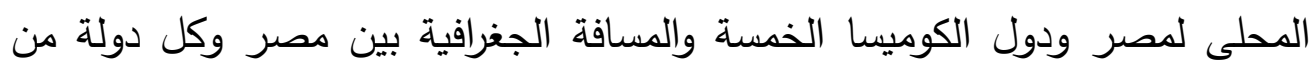

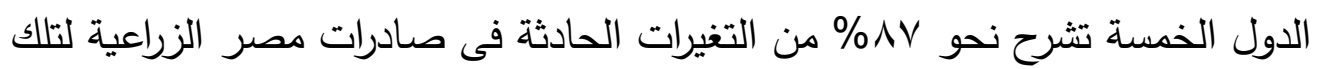
الدول، بينما ترجع حوالى با ا\% من التغيرات لعوامل اخرى غير منيرة مقيسة بالنموذج. 


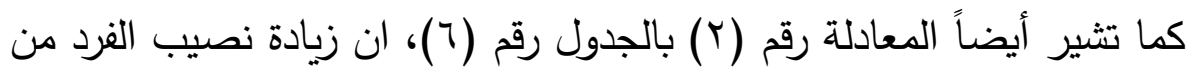

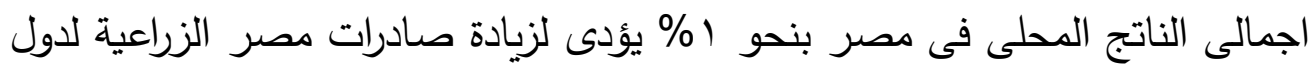

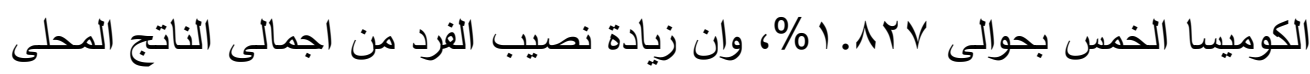

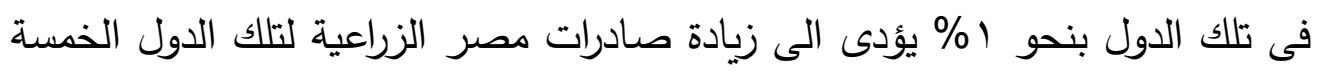

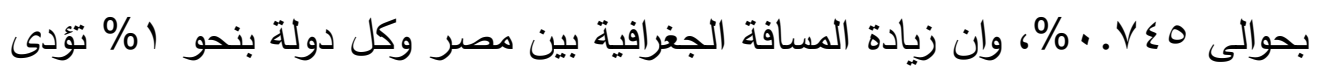

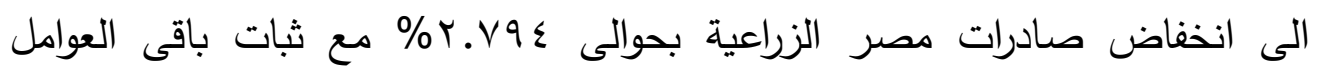

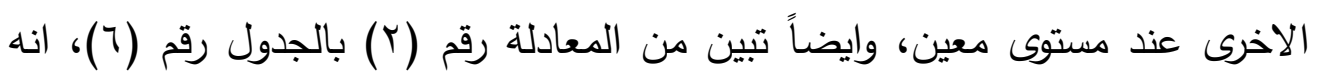

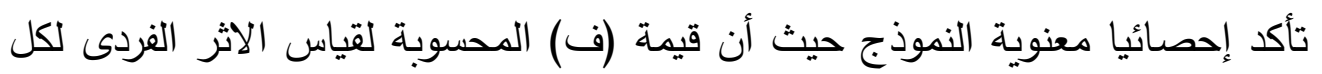

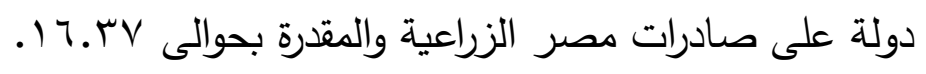

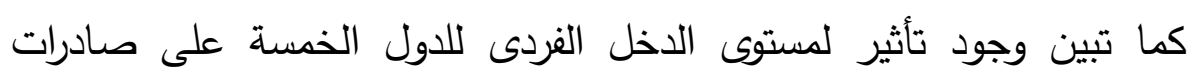

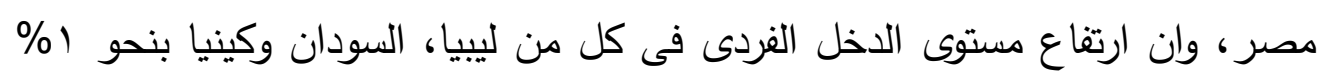

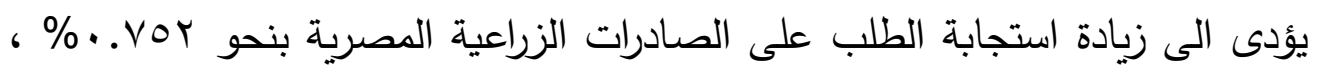

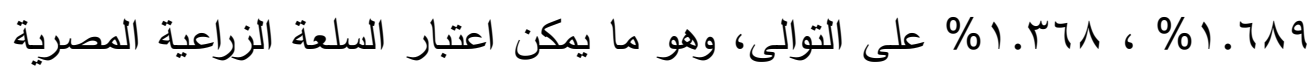

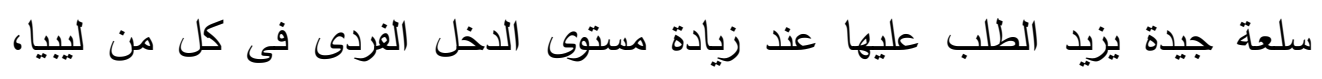

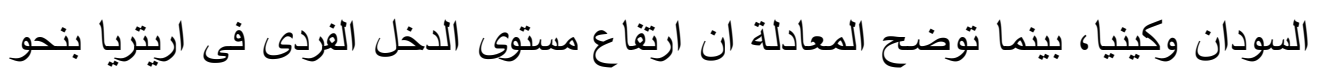

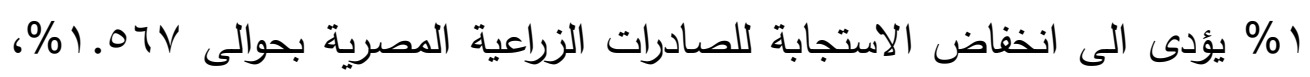

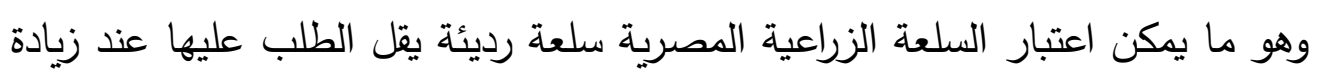
مستوى الدخل الفردى فى اريتريا.

- نتائج نموذج الجاذبية الاساسى للواردات الزراعية المصرية من دول الكوميسا:

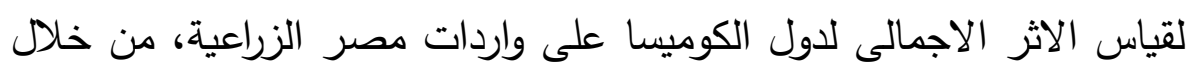

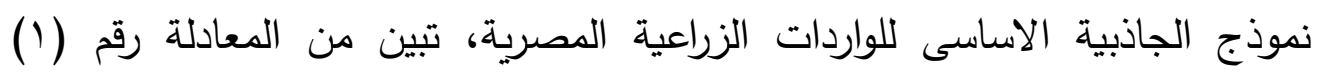

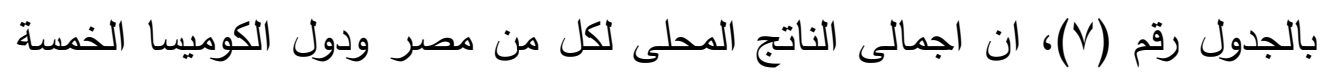

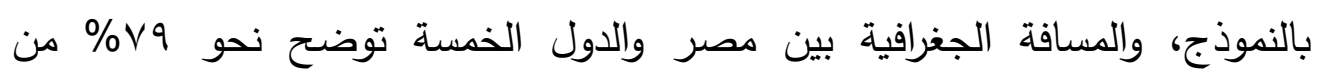

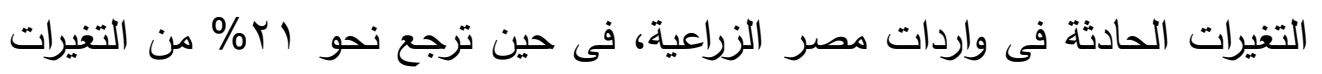

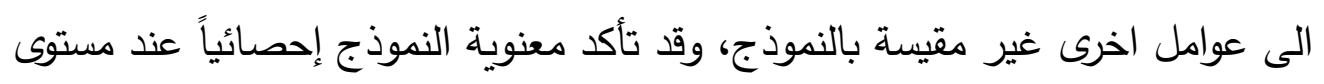

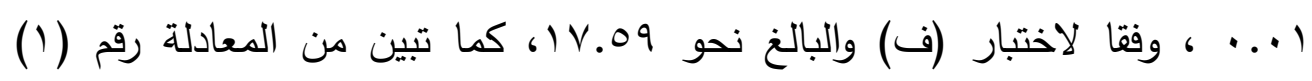

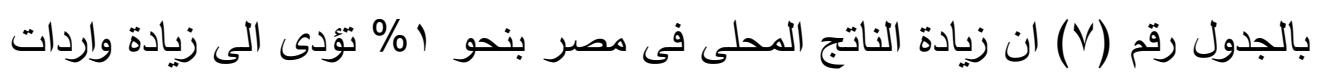




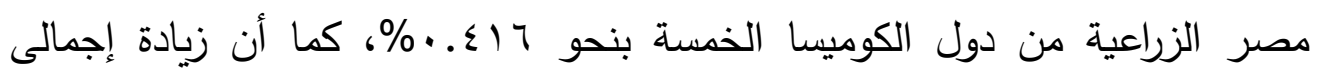

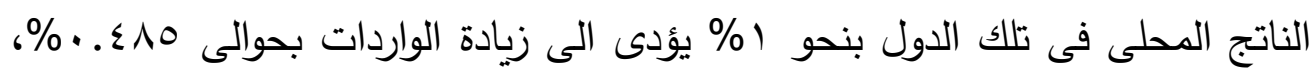

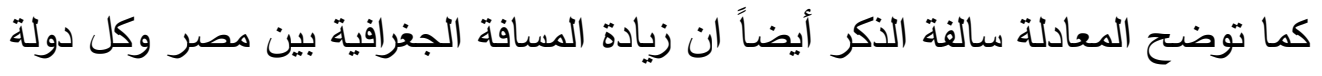

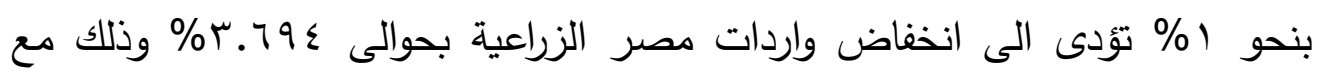
ثبات العوامل الاخرى عند مستوى معين. 
ياسر عبدالراضى و آخرون، دراسة تحليلية لتدفقات التجارة الخارجية بين مصر ودول الكوميسا.

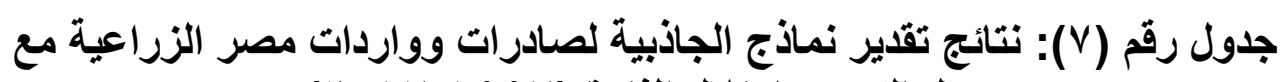

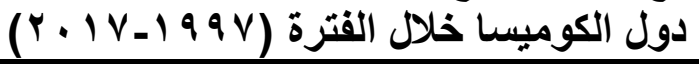

\begin{tabular}{|c|c|c|}
\hline \multicolumn{2}{|c|}{ الواردات Import (In Y } & \multirow[b]{2}{*}{ المتغير } \\
\hline $\begin{array}{c}\text { AGM } \\
(r)\end{array}$ & $\begin{array}{c}\text { BGM } \\
(1)\end{array}$ & \\
\hline \multirow[t]{3}{*}{ 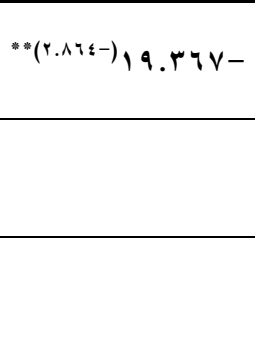 } & $" *(\varepsilon . Y Y \Lambda-)$ YV. $q \leq Y-$ & $\begin{array}{l}\text { ثابت المعادلة } \\
\text { (constant) }\end{array}$ \\
\hline & $($ r.A०v)..$\leqslant 17$ & $\begin{array}{r}\text { اجمالى الناتج المحلى لمصر } \\
\left(G D P_{i}\right)\end{array}$ \\
\hline & $* *(1 \ldots \varepsilon r \uparrow), \ldots \leqslant \wedge 0$ & $\begin{array}{r}\text { اجمالى الناتج المحلى لدول الكوميسا } \\
\text { (GDP })\end{array}$ \\
\hline 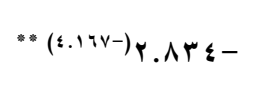 & $" 0(0.79 \leq-) \Psi .79 \leq-$ & $\begin{array}{r}\text { المسافة بين مصر ودول الكوميسا } \\
\text { (Distance) }\end{array}$ \\
\hline$* *(r . \wedge \cdot 1)$ ). $q^{\prime} \varepsilon$ & & 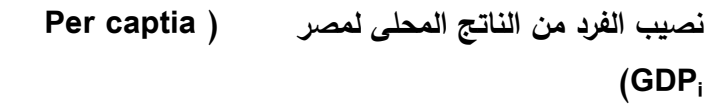 \\
\hline$"(r . \Delta r \Lambda-) . . r \wedge \leq-$ & & $\begin{array}{r}\text { Per captia ( نصيب الفرد من الناتج المحلى لاول الكوميسا } \\
\text { (GDPi }\end{array}$ \\
\hline $1 \ldots$ & $1 \ldots$ & $\mathbf{N}$ \\
\hline.$\wedge r$ & $\cdot . \vee 9$ & $\mathbf{R}^{2}$ \\
\hline$" 9.7 v$ & $" 18.09$ & F Test \\
\hline $119.04-$ & Iro.ro- & LLF \\
\hline
\end{tabular}

الارقام بين القوسين وأسفل معاملات الانحدار تثير الى قيم (ت) المحسوبة.

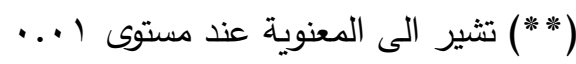

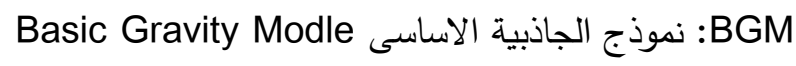

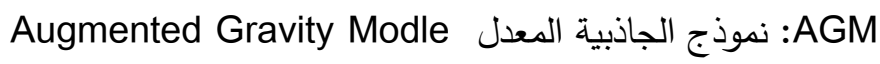

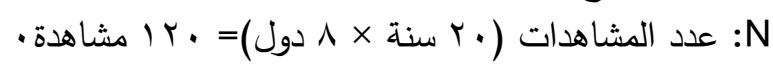
= معامل التحديد F Test LLF المصدر: جمعت وحسبت من بيانات الموقع الالكترونى للجهاز المركزي للتعبئة العامة والإحصاء، .$r .19$ 
وتبين المعادلة رقم (1) بالجدول رقم (^)، نتائج قياس الاثر الاجمالى لدول

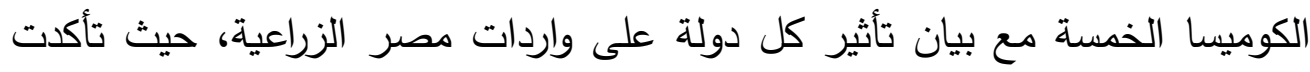
المعنوية الاحصائية وفقا لقيمة (ف) الححسوبة والتى تقدر بنحو

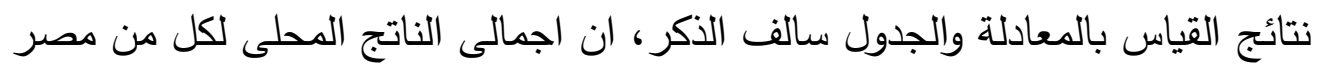

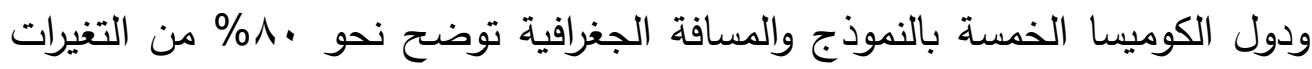

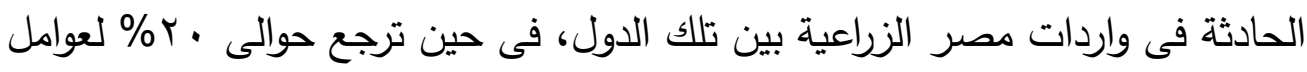

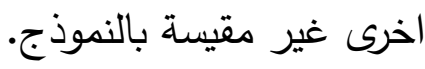

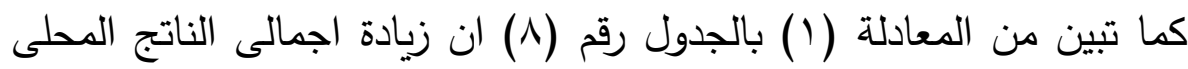

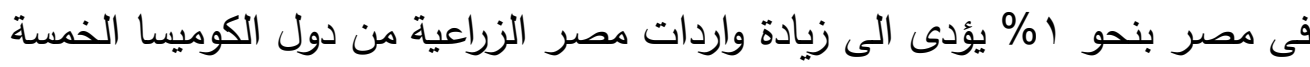

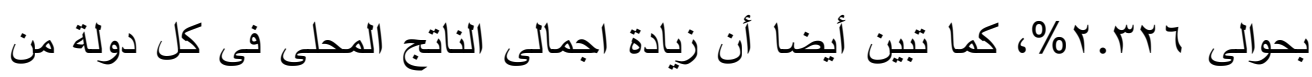

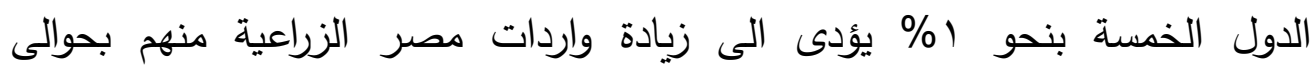

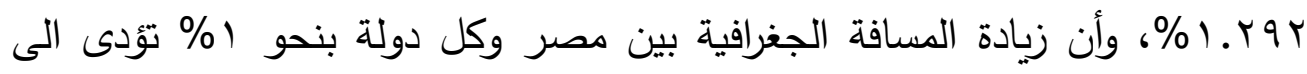

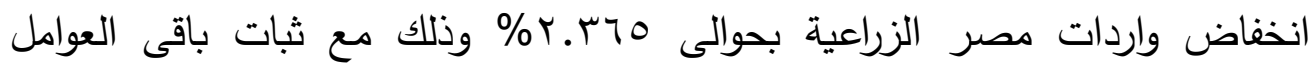

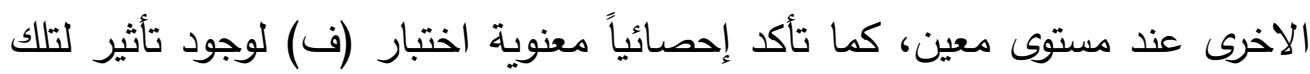

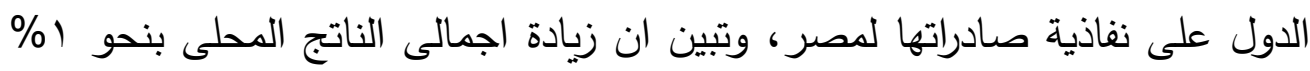

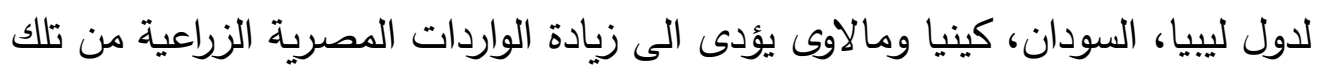

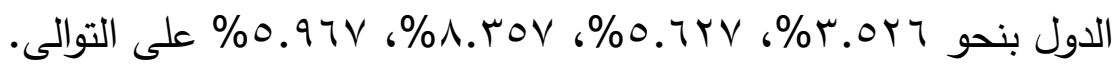

- نتائج نموذج الجاذبية المعدل للواردات الزراعية المصرية من دول الكوميسا:

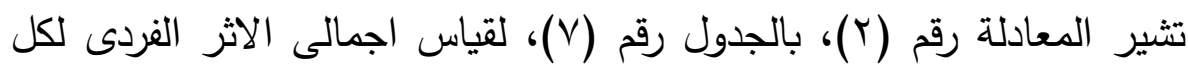

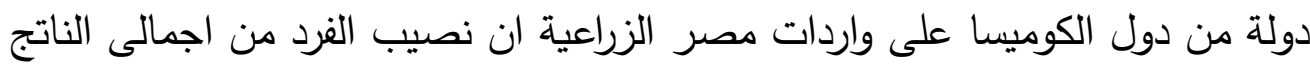

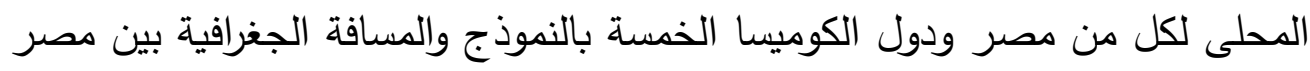

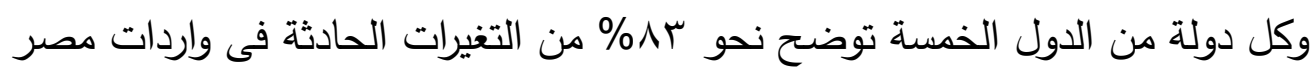

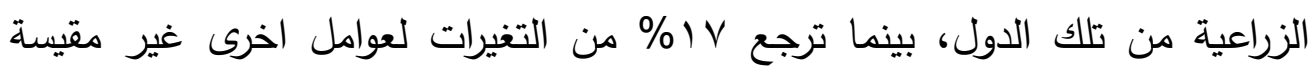

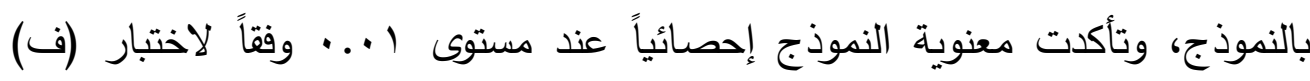

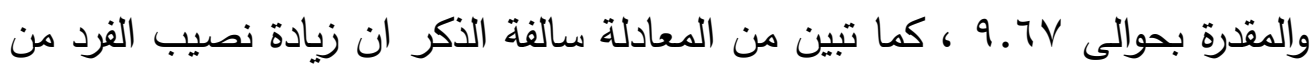

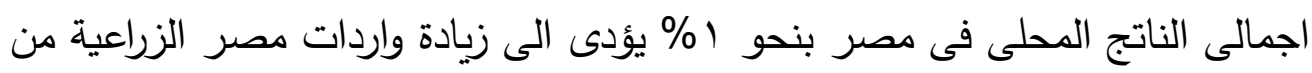

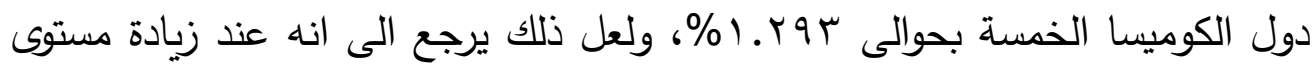


دخل الفرد فى مصر، فان طلبه الاستيرادى على منتجات دول الكوميسا الزراعية يزيد،

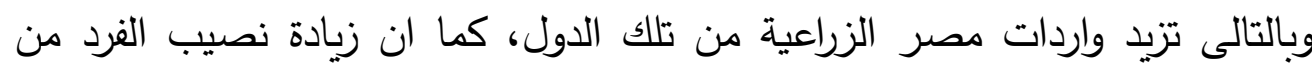

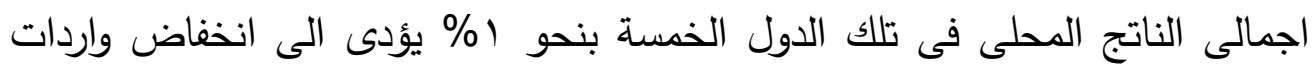

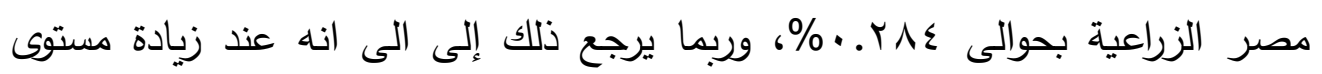

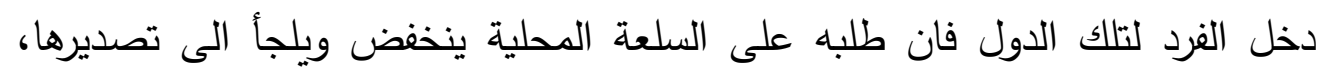
وبالتالى تزداد واردات مصر الزراعية من تلك الدول، كا تشير المعادلة رقم (Y)

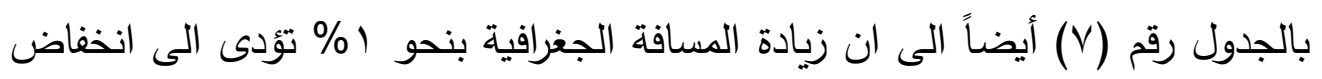

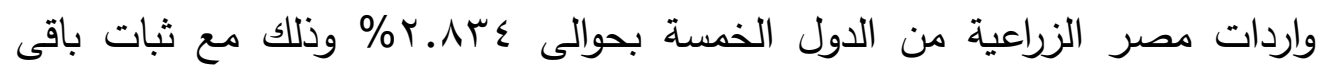
العوامل الاخرى عند مستوى معين. 


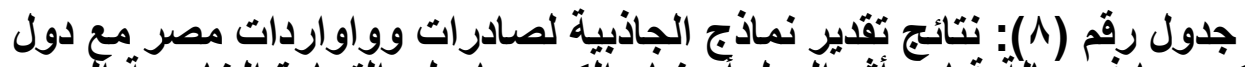

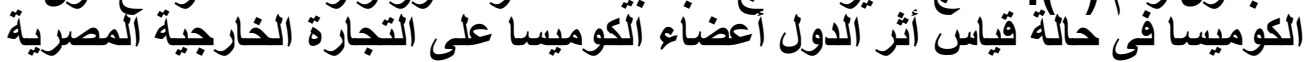

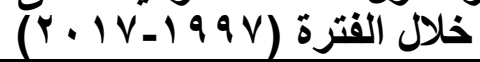

\begin{tabular}{|c|c|c|}
\hline \multicolumn{2}{|c|}{ Import (In Y Y الواردات } & \multirow[b]{2}{*}{ 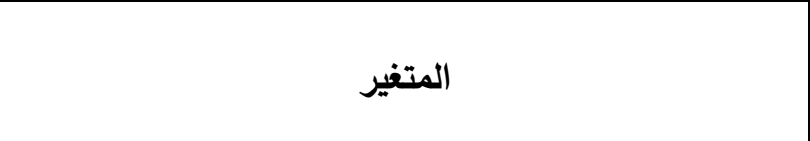 } \\
\hline$\underset{(r)}{\mathbf{A G M}}$ & $\underset{(1)}{\mathbf{B G M}}$ & \\
\hline & $($ (r.TYV)Y.MYY & اجمالى الناتج المحلى لمصر \\
\hline & $" *(r .4 Y V-) 1 . Y q r$ & اجمالى الناتج المحلى لدول الكوميسا \\
\hline$"(0.1+\mathrm{V}-) . . \wedge 0 \mathrm{Y}-$ & 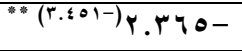 & المسافة بين مصر ودول الكوميسا \\
\hline$" *(r .10 V)^{4}$ Y.OrV & & تصيب الفرد من الناتج المحلى لمصر \\
\hline 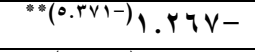 & & نصيب الفرد من الناتج المحلى لاول الكوميسا (Per captia GDPi) \\
\hline$"(r .90 \mathrm{~V}-) . . \wedge \mathrm{VV}-$ & 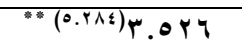 & Libya ليبيا \\
\hline$" .(5.07 \Lambda) 1.90 \mathrm{~V}$ & "*...Pa) $0.7 \mathrm{rV}$ & Sudan \\
\hline$(4.9 .90 \mathrm{~V}) 1 . \wedge 7 \mathrm{r}$ & $" *(\xi .0 Y \Lambda) \Lambda . \mu \diamond \nu$ & Kenya \\
\hline- & "* (0.14V) $0.97 \mathrm{~V}$ & Malawi \\
\hline "." $(7.09 \mathrm{~V}-) \xi .1$ Yo- & - & Eritrea \\
\hline $1 \cdots$ & $1 \ldots$ & $\mathbf{N}$ \\
\hline.$\vee \vee 4$ & $\cdot \wedge$. & $\mathbf{R}^{2}$ \\
\hline$m \leqslant \leqslant .71$ & $\leqslant 0.71$ & F Test \\
\hline 9Y.7V- & $90 . Y \wedge-$ & LLF \\
\hline
\end{tabular}

الارقام بين القوسين وأسفل معاملات الانحدار تثير الى قيم (ت) المحسوبة.

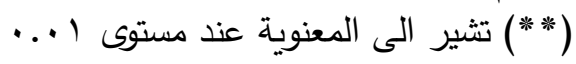

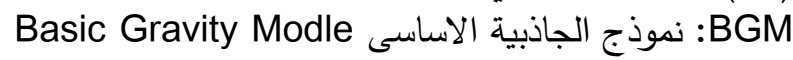

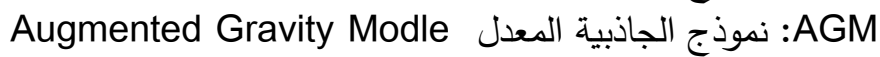

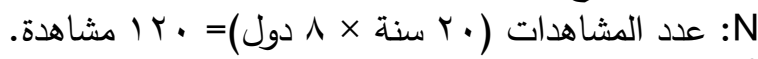
SeR R $^{2}$ F Test LLF

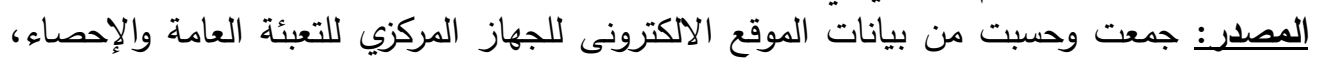
.$r \cdot 19$ ولقياس اجمالى الاثر الفردى بدول الكوميسا وبيان الاثر الفردى لكل دولة من

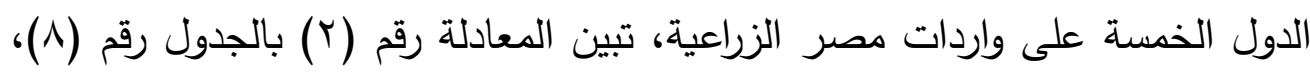

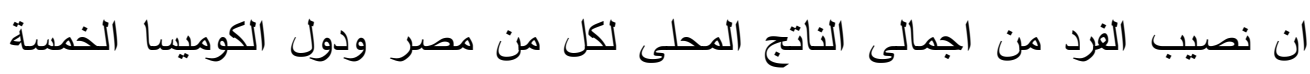

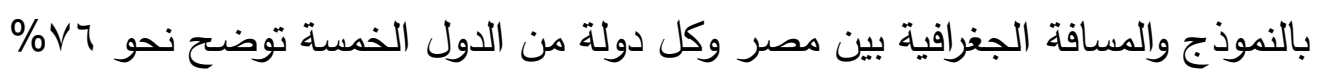

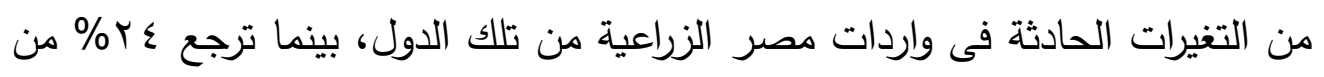
التغيرات الى عوامل اخرى غير مقيسة بالنموذج، وتوضح نفس المعادلة سالفة الذكر 


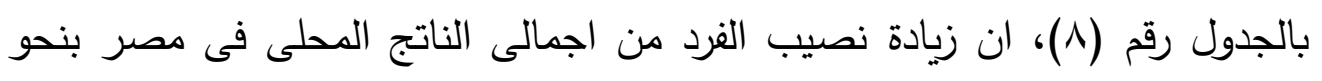

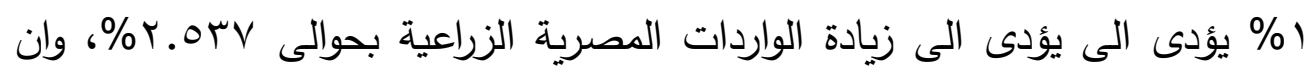

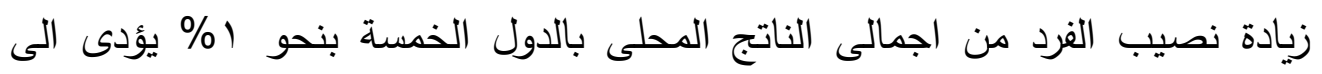

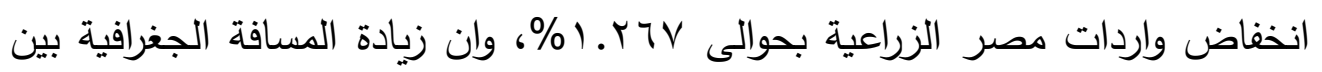

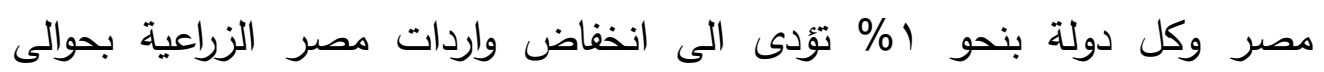

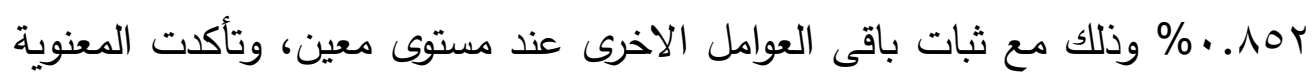

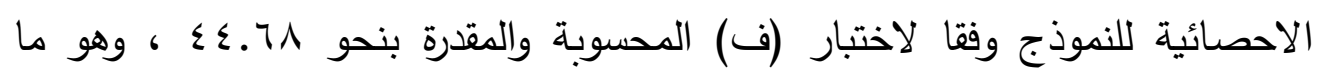

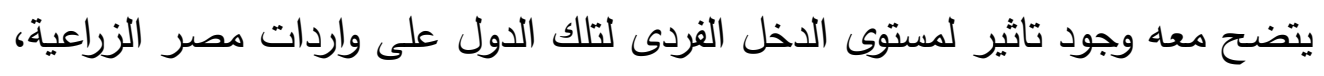

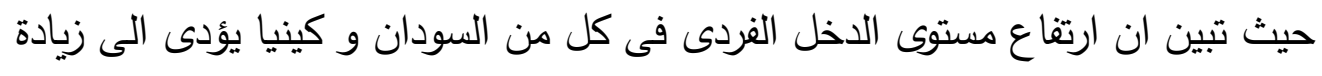

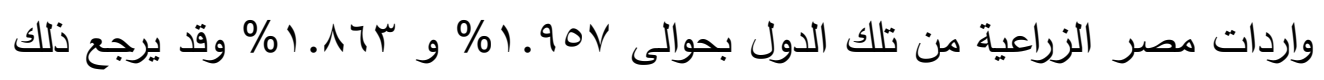

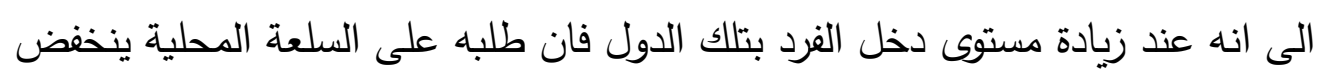

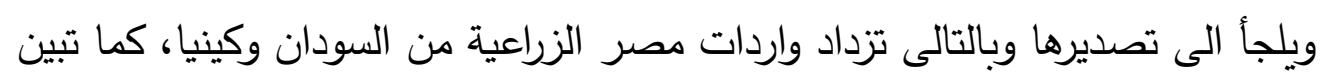

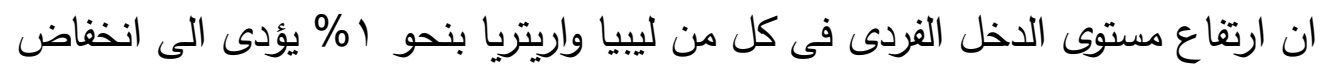

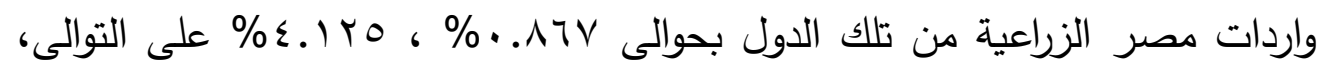

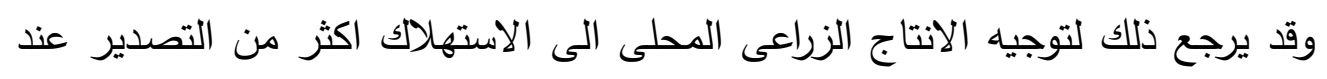
ارتفاع مستوى الدخل الفردى فى كل من ليبيا واريتريا. 


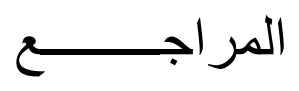

1-ابتسام بن يحى، " محددات التدفق التجارى الدولى فى ظل البيئة الدولية الجديدة للتجارة العالمية - دراسة تطبيقية باستخدام نموذج الجاذبية على حركة التجارة الخارجية فى الجزائر " ، جامعة فرحات عباس، كلية العلوم الاقتصادية والتجارية وعلوم التيسير، قسم العلوم الاقتصادية، تخصص اقتصاديات الاعمال والتجارة

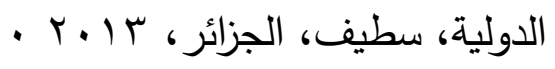
r- البنك الدولى، " مؤشرات التنمية العالمية " ، اعداد متفرقة ץ- الجهاز المركزى للتعبئة العامة والاحصاء، " نشرة التجارة الخارجية " ، اعداد متفرقة . ع - خديجة ححم الاعسر(دكتور)، " التجارة الخارجية لدول الكوميسا وامكانيات دعم القدرة التنافسية للصادرات المصرية لهذا السوق " ، مجلة البحوث التجارية المعاصرة، كلية التجارة، جامعة سوهاج، مصر، ، ... . . . . . ه-عماد عبد المسيح شحاتة(دكتور)، " الاثار الاقتصادية للتجارة الخارجية بين مصر والكوميسا باستخدام نموذج الجاذبية للتحليل المكانى "، المجلة المصرية للاقتصاد

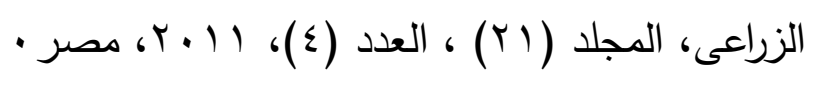

צ-على محم العبادلة، " محددات تدفق التجارة الخارجية لفلسطين-نموذج الجاذبية

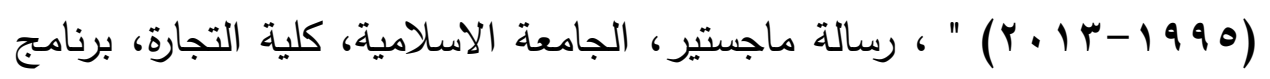

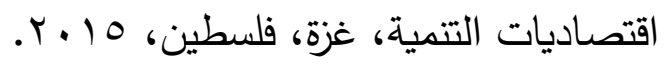

